\title{
Cluster approach to the prediction of thermodynamic and transport properties of ionic liquids
}

Zoe L. Seeger, Rika Kobayashi, and Ekaterina I. Izgorodina

Citation: The Journal of Chemical Physics 148, 193832 (2018); doi: 10.1063/1.5009791

View online: https://doi.org/10.1063/1.5009791

View Table of Contents: http://aip.scitation.org/toc/jcp/148/19

Published by the American Institute of Physics

\section{Articles you may be interested in}

Focus Article: Oscillatory and long-range monotonic exponential decays of electrostatic interactions in ionic liquids and other electrolytes: The significance of dielectric permittivity and renormalized charges

The Journal of Chemical Physics 148, 193701 (2018); 10.1063/1.5010024

Experimental validation of calculated atomic charges in ionic liquids

The Journal of Chemical Physics 148, 193817 (2018); 10.1063/1.5011662

Finding the best density functional approximation to describe interaction energies and structures of ionic liquids in molecular dynamics studies

The Journal of Chemical Physics 148, 193835 (2018); 10.1063/1.5013122

Mechanical heterogeneity in ionic liquids

The Journal of Chemical Physics 148, 193803 (2018); 10.1063/1.5008752

Thermodynamics and proton activities of protic ionic liquids with quantum cluster equilibrium theory

The Journal of Chemical Physics 148, 193822 (2018); 10.1063/1.5010791

Structural analysis of zwitterionic liquids vs. homologous ionic liquids

The Journal of Chemical Physics 148, 193807 (2018); 10.1063/1.5010983

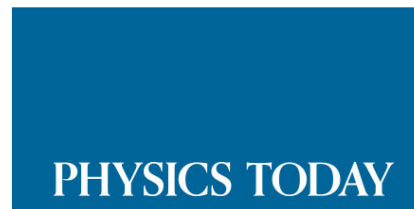




\title{
Cluster approach to the prediction of thermodynamic and transport properties of ionic liquids
}

\author{
Zoe L. Seeger, ${ }^{1}$ Rika Kobayashi, ${ }^{2}$ and Ekaterina I. Izgorodina ${ }^{1, a)}$ \\ ${ }^{1}$ School of Chemistry, Monash University, 17 Rainforest Walk, Clayton, VIC 3800, Australia \\ ${ }^{2}$ Australian National University, Leonard Huxley Building 56, Mills Road, Canberra, ACT 2601, Australia
}

(Received 20 October 2017; accepted 5 February 2018; published online 28 February 2018)

\begin{abstract}
The prediction of physicochemical properties of ionic liquids such as conductivity and melting point would substantially aid the targeted design of ionic liquids for specific applications ranging from solvents for extraction of valuable chemicals to biowaste to electrolytes in alternative energy devices. The previously published study connecting the interaction energies of single ion pairs (1 IP) of ionic liquids to their thermodynamic and transport properties has been extended to larger systems consisting of two ion pairs (2 IPs), in which many-body and same-ion interactions are included. Routinely used cations, of the imidazolium and pyrrolidinium families, were selected in the study coupled with chloride, tetrafluoroborate, and dicyanamide. Their two ion pair clusters were subjected to extensive configuration screening to establish most stable structures. Interaction energies of these clusters were calculated at the spin-ratio scaled MP2 (SRS-MP2) level for the correlation interaction energy, and a newly developed scaled Hartree-Fock method for the rest of energetic contributions to interaction energy. A full geometry screening for each cation-anion combination resulted in 192 unique structures, whose stability was assessed using two criteria-widely used interaction energy and total electronic energy. Furthermore, the ratio of interaction energy to its dispersion component was correlated with experimentally observed melting points in 64 energetically favourable structures. These systems were also used to test the correlation of the dispersion contribution to interaction energy with measured conductivity. Published by AIP Publishing. https://doi.org/10.1063/1.5009791
\end{abstract}

\section{INTRODUCTION}

The prediction of physicochemical properties of condensed systems such as ionic liquids from first principles represents a holy grail of theoretical chemistry. Ionic liquids have emerged as promising and superior alternatives to currently used electrolytes in electrochemical devices and solvents for a myriad of applications from $\mathrm{CO}_{2}$ capture to extraction of natural products from biowaste. ${ }^{1-11}$ Ideally, ab initio molecular dynamics simulations must be used for the accurate prediction of thermodynamic and transport properties of condensed materials as these allow for the inclusion of not only enthalpic but also entropic effects. To date, these types of simulations are limited to approximately $100 \mathrm{ps}$ for medium-sized simulation boxes of ionic liquids, not long enough to achieve statistically sound accuracy for individual ion trajectories and hence the calculation of bulk transport properties such as conductivity and viscosity. ${ }^{12,13}$ Classical and polarisable force fields have offered a tremendous capability for studying condensed systems as these allow for significantly longer simulations at the cost of reduced accuracy for bulk properties. ${ }^{12,14-27}$ In addition, these force fields do not allow us to study reactivity of ionic liquids as they cannot be used to break bonds. Due to a complex interplay of intermolecular forces in the bulk of ionic liquids, the predictive power of these force fields for

\footnotetext{
a)Author to whom correspondence should be addressed: katya.pas@ monash.edu
}

ionic liquids has not reached its full potential as force fields are continuing to be further improved.

Static quantum chemical calculations of single ion pairs have been used as a simple model to predict physicochemical properties of ionic liquids with varying success. ${ }^{13}$ Recently, our group has shown how the combination of the second law of thermodynamics and interaction energies of single ion pairs (1 IP) may be used to understand the behaviour of melting points of ionic liquids. ${ }^{28}$ It was established that the ratio of interaction energy to its dispersion component could be correlated with melting point $\left(T_{m}\right)$ for a range of $N$-methyl- $N$ alkylpyrrolidinium- and $N$-methyl- $N$-alkylimidazolium-based ionic liquids as shown in Eq. (1). Additionally, the dispersion component of the interaction energy in these systems was shown to correlate well with conductivity, ${ }^{28,29}$

$$
T_{m}=f\left(\frac{E_{I N T}}{E_{I N T}^{d i s p}}\right) .
$$

However, the single ion pair model does not account for manybody effects found to be far from negligible in ionic liquids..$^{13,30}$ These effects are shown to increase not only with increasing alkyl chain on the cation ${ }^{31-33}$ but also due to the bulky nature of ionic liquid ions. ${ }^{30}$ This finding suggests that largerscale clusters are necessary in order to accurately account for intermolecular forces observed in the bulk of ionic liquids.

In addition to molecular dynamics and single ion models, the quantitative structure-property relationship (QSPR) approach, Volume-Based Thermodynamics (VBT), and 
conductor like screening model for real solvents (COSMORS) have been employed in relating the ionic liquids' electronic structure to their thermodynamic and transport properties. QSPR, ${ }^{34-36} \mathrm{VBT}^{37,38}$ and COSMO-RS ${ }^{39,40}$ have accurately predicted physicochemical properties based on $a b$ initio calculations of single ion pairs and parametrization of the underlying formulation for different ionic liquid types. The required parametrization results from the omission of many-body effects, thus affecting the transferability of these techniques to novel systems. ${ }^{13}$ An example of this was explained in a review by Valderrama, ${ }^{36}$ which stated that QSPR models in the literature give melting points to within $25 \mathrm{~K}$ in the best case and $102 \mathrm{~K}$ in the worst case. Improved predictions are possible with the sacrifice of narrowing down the type of species present in the training set and thus limiting the ionic liquids for which the model can be applied. A satisfactory balance between accuracy and transferability has not been found. Relatively few publications have attempted to use VBT to predict melting point as it has similar shortcomings as QSPR. Gutowski ${ }^{41}$ used this method instead for the prediction of lattice enthalpies and it was found that average errors of less than $15 \mathrm{~kJ} \mathrm{~mol}^{-1}$ were achieved only when extra parametrisation was applied for each ionic liquid family. The result reflects the disregard of dispersion interactions which are not correlated with an ion pair's volume. COSMO-RS has also been applied to the prediction of thermodynamic and transport properties. The Krossing group ${ }^{42}$ has applied a least-squares regression to a large database of molecules reporting an average error of $36 \mathrm{~K}$, later including added parametrisation for the ring interaction enthalpy and van der Waals interaction enthalpy, which only slightly decreased the average error and reduced the maximum error from $116 \mathrm{~K}$ to $89 \mathrm{~K}$. The outliers suggest that the relationship does not viably connect the descriptors to the melting point. This is observed again when conductivity is considered. ${ }^{43}$

A cluster approach originally proposed by Ludwig has been used to predict thermodynamic properties (i.e., entropy, enthalpy of vaporization) of water and ionic liquids using minimum energy structures of up to 14 ion pairs. ${ }^{44-47}$ For $\left[\mathrm{C}_{1} \mathrm{mim}\right][\mathrm{SCN}]$, binding energies per ion pair converged in the clusters of 10 IPs highlighting the importance of manybody effects over a long range. ${ }^{46}$ The approach was also used to correlate $\mathrm{RHF} / 3-21 \mathrm{G}$ binding energies and experimental melting points of imidazolium-based $\mathrm{NTf}_{2}{ }^{-}$ionic liquids and would need to be tested with correlated levels of theory. ${ }^{48,49}$ Weinhold developed the quantum cluster equilibrium (QCE) methodology that requires a series of increasing cluster sizes to extract partition functions and hence the Gibbs free energy and other thermodynamic properties. ${ }^{50,51}$ Ludwig and Weinhold used the QCE methodology to treat clusters of small neutral species such as methanol, ammonia, and water. ${ }^{52-59}$ The Kirchner group has recently showed that the level of theory is extremely important in the treatment of hydrogen bonding. ${ }^{60-62}$ Overall, the cluster approach has been rather successful in extracting thermodynamic and spectroscopic properties of ionic liquids. ${ }^{63-67}$

However, the direct correlation of physicochemical properties with cluster energies has not yielded interpretable relationships. This is partly due to the difficulty in predicting the crystal structure which governs the physicochemical properties of the materials and is best modeled by periodic structures. However, the size of these periodic structures needs to vary depending on the property being calculated to ensure meaningful prediction. To find energies of these large systems with theories able to accurately represent dispersion is challenging. Correlations of single ion pair structures were attempted with transport and thermodynamic (such as melting point) properties in the past and it was shown that their energies do not represent the bulk properties of the ionic liquid. ${ }^{28,68,69}$ Recently, many-body effects have been shown to be significant in large clusters of ionic clusters. ${ }^{28,70,71}$ Therefore, it has become clear that in order to reliably predict physicochemical properties of ionic liquids, large scale systems, those of many ion pairs, must be used. To date, the only spectroscopic properties have been successfully determined. ${ }^{63-67}$

Muller-Dethlefs and Hobza ${ }^{72}$ published a review that highlighted the importance of interaction energy in describing condensed systems. While interaction energy is magnitudes smaller than the covalent interactions, these noncovalent interactions control dynamics of clustered systems and are made up of electrostatics, induction, dispersion, and exchangerepulsion. While many quantum methods deal with electrostatics quite well, to accurately reproduce physicochemical properties dispersion must be properly accounted for. Furthermore, the non-additive components, induction and exchangerepulsion, need to be considered in larger clusters to mimic the forces in the bulk. Since large clusters are dominated by cumulative causal motion, an equilibrium structure is not truly representative of the system and thereby minima of the potential energy surface are better found by minimising the Gibbs free energy. In practice, interaction energy is commonly used as the criterion to determine the most stable structure. The interaction energy is an artefact and is widely used in largescale calculations due to the simplicity of the calculation. Interaction energy is not observable by experiment and lacks important contributions such as deformation energy associated with the energy penalty due to the changes in geometry of interacting molecules/ions, zero-point vibrational energy, entropic contribution, and temperature correction. Interaction energy is an excellent quantity to benchmark quantum chemical methods. It might not be as reliable as in determining the most stable structure. To determine realistic minima on the potential energy surfaces, free energy that includes the aforementioned contributions is preferred. This can also be achieved by analysing a series of non-equilibrium geometries on the potential energy surface. ${ }^{73}$

It is well known that single ion pairs do not accurately represent the interactions in an ionic liquid. ${ }^{68,70,74-77}$ The importance of many-body effects, induction and dispersion, is magnified by the additional ion pairs and therefore clusters must be considered to extract correct ionic liquid properties. Therefore, an extensive study of 2 ion-paired clusters of 24 ionic liquids of imidazolium and pyrrolidinium families has been conducted to investigate: whether total energy and interaction energy can be reliably used as criteria for finding thermodynamically stable geometries, the correlation of melting point with the fundamental energetic components of interaction energy, and the correlation of the dispersion component 
to interaction energy with conductivity. The last two points are then compared to the study of ion pair systems ${ }^{28}$ to tease out the effect of including the same ion interactions to the energy components. There is also a description of a scaled HartreeFock method to produce accurate HF interaction energies of many ion-paired clusters of ionic liquids at a small basis set.

\section{THEORETICAL PROCEDURES}

All geometry optimisations were performed with the Fragment Molecular Orbital (FMO) approach ${ }^{78,79}$ accounting for the two-body correction (i.e., FMO2) coupled with the recently developed spin-ratio scaled second-order Møller-Plesset perturbation method (SRS-MP2) which was designed to achieve high accuracy for interaction energies in multi-scale clusters of ionic liquids. ${ }^{80}$ The SRS-MP2 method called a spin ratio-based scaled MP2 method is an improved version of the original spin-component scaled second-order Møller-Plesset perturbation method scaled for ionic liquids (SCS-IL-MP2) and was designed to work equally well for ionic and neutral complexes. ${ }^{30}$ The advantage of the method lies in its high accuracy (maximum errors below $4 \mathrm{~kJ} \mathrm{~mol}^{-1}$ ) and the inclusion of basis set superposition error into the scaling coefficients of the MP2 correlation energy, thus allowing for more accurate geometry optimisations of multi-scale clusters without the need for a counterpoise correction. In this work, the SRS-MP2 method was combined with Dunning's cc-pVDZ basis set for geometry optimisations and only the opposite-spin (OS) component was scaled to 1.752 to improve correlation energy (for more details, see Ref. 30). All optimized structures were subjected to single-point energy calculations using two- and three-body corrections (i.e., FMO3) coupled with the SRS-MP2 method by scaling the OS component with 1.640 and Dunning's cc-pVTZ basis set. Our group recently showed that the three-body correction was already sufficient to accurately approximate MP2 interaction energies in multi-scale clusters of ILs. ${ }^{70}$ Non-counterpoise corrected HF interaction energies calculated at the cc-pVTZ basis set were scaled to reproduce those of HF/aug-cc-pVQZ using the recently developed scheme, which is discussed in full detail below. No cutoffs for both two-electron integrals and many-body effects were employed in the FMO calculations presented. Calculations were performed using the GAMESS-US, ${ }^{81}$ PSI $4,{ }^{82}$ and Gaussian09 ${ }^{83}$ packages of quantum chemical methods.

Deformation energies were calculated using the energy of the ion in the configuration it adopts in the cluster and subtracting the energy of the ion optimised in a vacuum, resulting in the energy that the ion uses to contort in its environment.

The mean of signed errors, called mean for simplicity $(\bar{x})$, the mean absolute error (MAE), the standard deviation, $S D=\sqrt{\sum_{i}^{n}\left(x_{i}-\bar{x}\right)^{2} /(N-1)}$, of $N$ instances where $x_{i}$ in an instance, and the maximum absolute error $(\max )$ are presented for data predictions.

\section{RESULTS AND DISCUSSION}

\section{Construction of two ion-paired clusters}

Commonly used imidazolium $\left(\mathrm{C}_{\mathrm{n}} \mathrm{mim}^{+}\right)$and pyrrolidinium $\left(\mathrm{C}_{\mathrm{n}} \mathrm{mpyr}^{+}\right)$cations were considered with the alkyl chain increasing from methyl to $n$-butyl $(\mathrm{n}=1-4)$. Two ionpaired clusters were constructed using low energy configurations of single ion pairs coupled with chloride, tetrafluoroborate, and dicyanamide $\left(\mathrm{N}(\mathrm{CN})_{2}{ }^{-}\right)$from our previous study. ${ }^{28}$ 15 and 16 different types of cluster configurations were geometry optimised for the imidazolium- and pyrrolidinium-based cations, respectively (for more details, see Fig. 1). In the case of the $\mathrm{C}_{n} \mathrm{mim}^{+}$cation, the imidazolium rings are considered either in a $\pi^{+}-\pi^{+}$stacked arrangement ${ }^{84}$ (see configurations p1, p2a, p2b, p3a, p3b, p8a, and p8b in Fig. 1) or an alternating charge arrangement (configurations $\mathrm{p} 4-\mathrm{p} 7$ in Fig. 1). In the case of the pyrrolidinium cation, only alternating charge structures were considered due to the absence of a delocalised $\pi$-conjugated ring. Increasing alkyl chains were also allowed to interact through van der Waals dispersion, thus leading to additional configurations for both the imidazolium cations [see configurations pna $(n=2-8)$ in Fig. 1] and the pyrrolidinium cations (see configurations p1, p2a, p2b, p3, and p9 in Fig. 1). In addition, the alkyl chains, R, were also allowed to alternate their position in configurations p1 and p4-p7 in the pyrrolidinium clusters, thus generating additional configurations analogous to $\mathrm{p} n \mathrm{~b}$ configurations ( $n=2-8$ ) in the imidazolium clusters (not shown in Fig. 1 for the sake of simplicity). Some of the initial ionic clusters optimized to the same structure. Overall, between 5 and 12 unique structures were located for the selected combinations of the cation and anion, with the total number of 194 clusters being optimized (for more details, see the supplementary material).

\section{Lowest energy configurations of $\mathbf{2}$ ion-paired clusters}

Figure 2 shows the lowest energy structures for the imidazolium and pyrrolidinium ionic liquids studied, with SRS-MP2/cc-pVTZ total electronic energies being used to determine the lower energy structures.

Analysis of Fig. 2 reveals that both the anion and the alkyl chain appear to determine the energetically preferred arrangement in ionic liquids. Further in the text, abbreviations of two ion-paired configurations are taken from Fig. 1.

For imidazolium-based clusters with the $\mathrm{BF}_{4}{ }^{-}$anion, there is an energetic preference for the alternate charge arrangement such as the p4a structure in Fig. 1, with the stacking configuration having a much higher energy by at least $21 \mathrm{~kJ} \mathrm{~mol}^{-1}$ regardless of the alkyl chain length. The alternating charge arrangement, in which alkyl chains interact such as the structure $\mathrm{p} 4 \mathrm{a}$ or the planes of the imidazolium ring are perpendicular to each other such as the $\mathrm{p} 7 \mathrm{a} / \mathrm{b}$ structures, becomes the second energetically preferred configuration. As seen in Fig. 2, for the $\left[\mathrm{C}_{\mathrm{n}} \mathrm{mim}\right] \mathrm{Cl}$ clusters, the $\pi^{+}-\pi^{+}$stacking configuration (p2a/b and p8b) competes with the alternative arrangement (p4b) and becomes preferred by only a couple of $\mathrm{kJ} \mathrm{mol}^{-1}$. For longer alkyl chains starting with ethyl, the $\mathrm{p} 7 \mathrm{~b}$ configuration falls within $10 \mathrm{~kJ} \mathrm{~mol}^{-1}$. Other optimized configurations are much higher in energy, between 20 and $40 \mathrm{~kJ} \mathrm{~mol}^{-1}$. For the imidazolium-based clusters with the $\mathrm{N}(\mathrm{CN})_{2}{ }^{-}$anion, the alternating arrangement $(\mathrm{p} 4 \mathrm{a})$ is preferred for shorter alkyl chains such as methyl and ethyl, with the $\pi^{+}-\pi^{+}$stacking (p2a and p2b) becoming most energetically stable for longer alkyl chains such as propyl and butyl. The alternate arrangement 


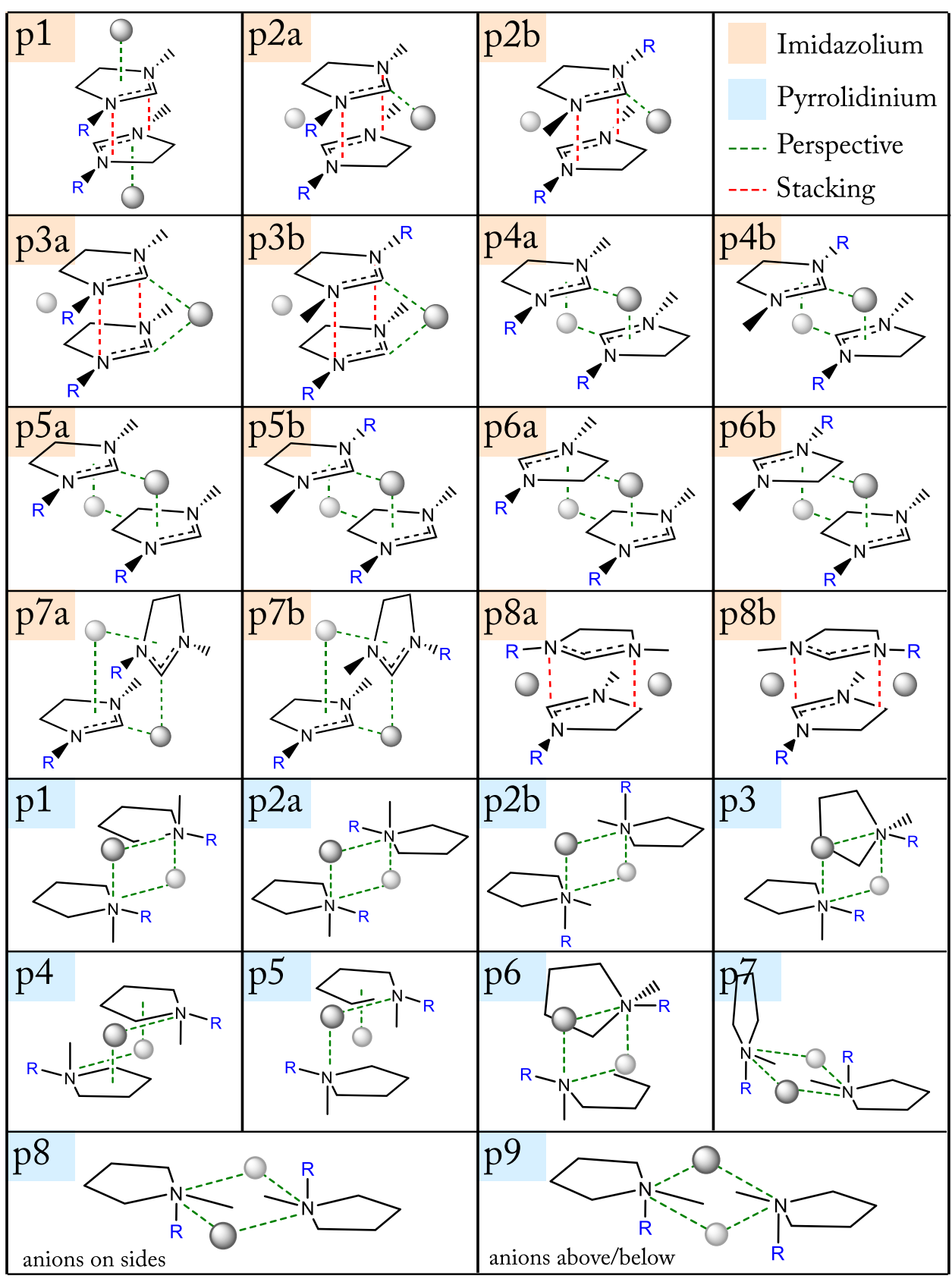

FIG. 1. Schematic of starting geometries of 2 ion-paired clusters $\left[\mathrm{X}=\mathrm{Cl}^{-}\right.$, $\mathrm{BF}_{4}^{-}$, and $\left.\mathrm{N}(\mathrm{CN})_{2}{ }^{-}\right]$. Green dashed lines show the shortest distance between the cation and anion, whereas red dashed lines indicative $\pi^{+}-\pi^{+}$in imidazolium-based ionic liquids. configurations (p4a/b and p5a) are still within $10 \mathrm{~kJ} \mathrm{~mol}^{-1}$. Apart for a few exceptions such as $\left[\mathrm{C}_{1} \mathrm{mim}\right] \mathrm{X}\left(\mathrm{X}=\mathrm{BF}_{4}{ }^{-}, \mathrm{Cl}^{-}\right.$, and $\mathrm{N}(\mathrm{CN})_{2}{ }^{-}$) and $\left[\mathrm{C}_{2} \mathrm{mim}\right]\left[\mathrm{BF}_{4}\right]$, the rest have between 3 and 6 configurations falling within $10 \mathrm{~kJ} \mathrm{~mol}^{-1}$, thus giving rise to a large number of 2 ion paired configurations.

In the case of the $\left[\mathrm{C}_{\mathrm{n}} \mathrm{mpyr}\right]\left[\mathrm{BF}_{4}\right]$ ionic liquids, the $\mathrm{p} 2$ configuration is the most stable for the methyl and ethyl substitutions on the pyrrolidinium ring and this changes to $\mathrm{p} 1$ for longer chains, with the alkyl chain preferring to interact with the pyrrolidinium ring. There are between 2 and 5 optimized configurations for each alkyl chain within $10 \mathrm{~kJ} \mathrm{~mol}^{-1}$. For the chloride-based clusters, the situation becomes reversed, with the $\mathrm{p} 1$ configuration being preferred for shorter alkyl chains and p2 for longer alkyl chains. The chloride-based clusters are also unusual as there are only 2 ionic configurations falling within $10 \mathrm{~kJ} \mathrm{~mol}^{-1}$ of each other, with the rest of the optimised structures having much higher energies of up to $45 \mathrm{~kJ} \mathrm{~mol}^{-1}$. For the dicyanamide anion, between 4 and 7 configurations fall within $10 \mathrm{~kJ} \mathrm{~mol}^{-1}$, with the only exception being $\left[\mathrm{C}_{3} \mathrm{mpyr}\right]\left[\mathrm{N}(\mathrm{CN})_{2}\right]$, for which only one configuration (p3) was located in the $10 \mathrm{~kJ} \mathrm{~mol}^{-1}$ range. For the methyl and ethyl groups of $\mathrm{C}_{3} \mathrm{mpyr}^{+}$, at least three configurations are within $2 \mathrm{~kJ} \mathrm{~mol}^{-1}$, with the butyl chain having 3 configurations within $3 \mathrm{~kJ} \mathrm{~mol}^{-1}$. The rest of the configurations have higher energies of up to $66 \mathrm{~kJ} \mathrm{~mol}^{-1}$. These findings indicate that anions with multiple interaction sites, such as tetrafluoroborate and dicyanamide, tend to have a number of energetically preferred configurations on the potential energy surface, whereas chloride usually produces a small number of these configurations.

The Hunt group studied 2 ion-paired clusters of the 1,3-dimethyl-imidazolium cation coupled with the 


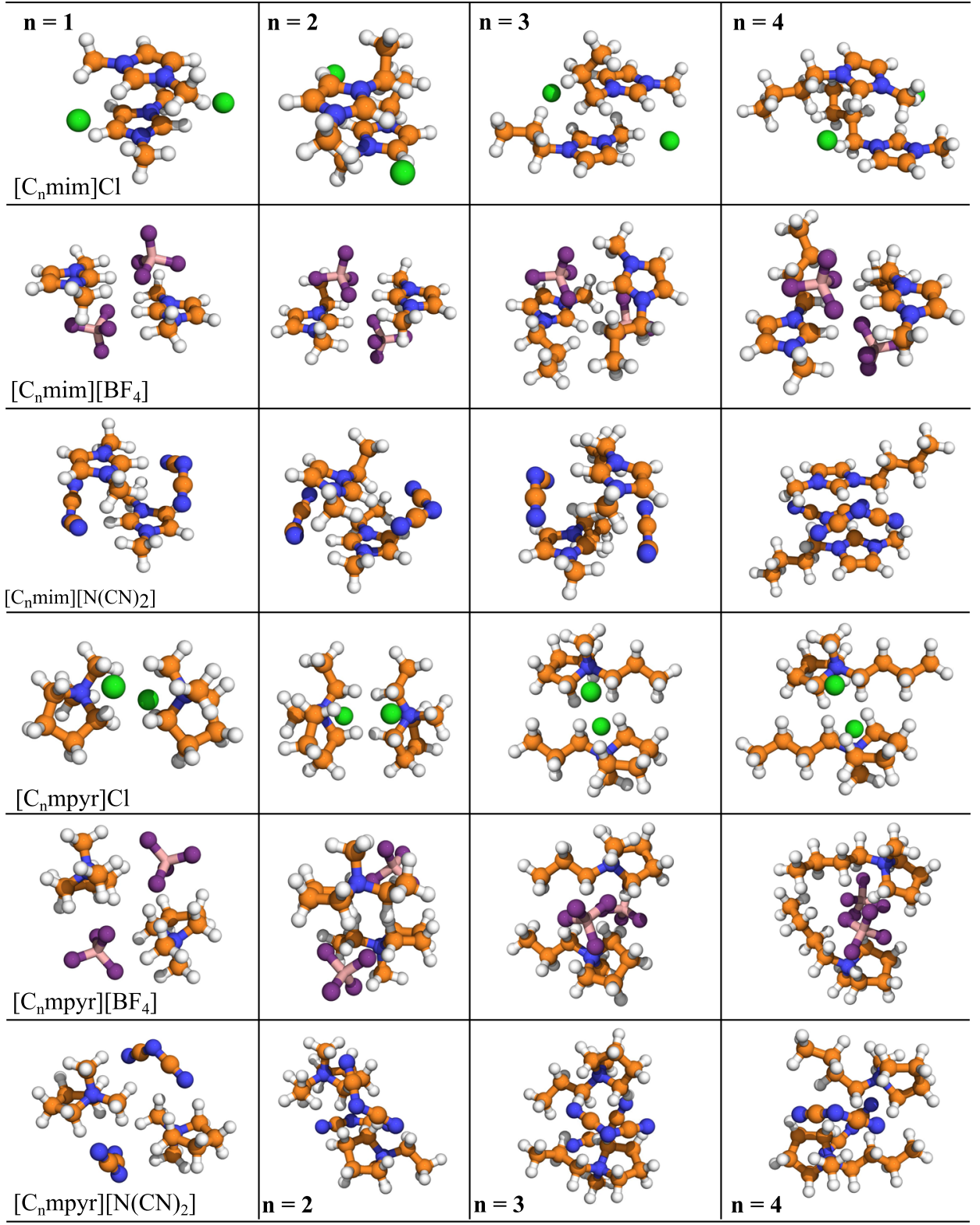

FIG. 2. Lowest energy configurations of $\left[\mathrm{C}_{\mathrm{n}} \operatorname{mim}\right] \mathrm{X}$ and $\left[\mathrm{C}_{\mathrm{n}} \mathrm{mpyr}\right] \mathrm{X}$ ionic liquids, where $\mathrm{n}=1-4$ and $\mathrm{X}=\mathrm{Cl}^{-}, \mathrm{BF}_{4}{ }^{-}$, and $\mathrm{N}(\mathrm{CN})_{2}{ }^{-}$. tetrafluoroborates and chloride anions at the B3LYP-D3/augcc-pVTZ level of theory. ${ }^{85,86}$ D3 represents Grimme's third generation empirical correction for dispersion. ${ }^{87-89}$ It has been shown before that many density functional theory (DFT) functionals such as B3LYP suffer from poor description of dispersion forces. ${ }^{29,91}$ The inclusion of the empirical dispersion correction ${ }^{90}$ usually results in the decrease of errors in interaction energies to $10 \mathrm{~kJ} \mathrm{~mol}^{-1}$. There are obvious discrepancies between our and previously published data. In the case of $\left[\mathrm{C}_{1} \mathrm{mim}\right] \mathrm{Cl}$, only two configurations were located within $10 \mathrm{~kJ} \mathrm{~mol}^{-1}$, whereas as many as 6 were identified with B3LYP-D3. There is good agreement between the two most stable structures located, whereas the four additional structures located with B3LYP-D3 had electronic energies well above $18 \mathrm{~kJ} \mathrm{~mol}^{-1}$ in energy as calculated with SRS-MP2/cc-pVTZ. A similar situation is observed for $\left[\mathrm{C}_{1} \mathrm{mim}\right]\left[\mathrm{BF}_{4}\right]$, for which only two configurations within $10 \mathrm{~kJ} \mathrm{~mol}^{-1}$ were located in our study, whereas 3 configurations were found with B3LYP-D3. The SRS-MP2/cc-pVTZ configurations are in good agreement geometry-wise and relative energy-wise with the previously published data, whereas the third favourable configuration with B3LYP-D3 was found to have an energy of $26 \mathrm{~kJ} \mathrm{~mol}^{-1}$ higher when optimized with SRS-MP2 and was therefore discarded in our study. It has to be noted that configurations that were within $2-3 \mathrm{~kJ} \mathrm{~mol}^{-1}$ of the lowest energy geometry were in good agreement between the SRS-MP2 and B3LYP-D3 levels of theory. Obviously, B3LYP-D3 could locate the lowest energy configurations for $\left[\mathrm{C}_{1} \mathrm{mim}\right]\left[\mathrm{BF}_{4}\right]$ and $\left[\mathrm{C}_{1} \mathrm{mim}\right] \mathrm{Cl}$. It appears that B3LYP-D3 has difficulty in the prediction of energy of other configurations due to a complex interplay of fundamental forces, with the combination of the B3LYP functional and D3 correction needing to be tested further to confirm its reliability for ionic liquids. These findings highlight the importance of using a reliable and accurate level of theory even for geometry optimisations of large-scale clusters of ionic liquids.

In summary, the increasing alkyl chain length leads to a large number of energetically preferred configurations. The 
availability of multiple interaction sites on the anion such as tetrafluoroborate and dicyanamide tends to also increase the number of viable configurations. There are a few exceptions to this rule. $\left[\mathrm{C}_{1} \operatorname{mim}\right] \mathrm{X}\left(\mathrm{X}=\mathrm{BF}_{4}, \mathrm{Cl}\right.$, and $\left.\mathrm{N}(\mathrm{CN})_{2}\right)$ and $\left[\mathrm{C}_{\mathrm{n}} \mathrm{mpyr}\right] \mathrm{Cl}(\mathrm{n}=1-4)$ clusters have either one or two configurations within $10 \mathrm{~kJ} \mathrm{~mol}^{-1}$. The ionic arrangement in the most energetically stable configuration is strongly dependent on the cation and anion combination. It appears that a full conformational screening is required for each cation-anion combination to determine the most stable structures. This might also explain complexity in thermodynamic and transport properties that are not transferrable between each family of cations.

\section{Interionic distances and dispersion forces in 2 ion-paired clusters}

Table I presents ranges of interionic distances in the optimized 2 ion-paired clusters whose electronic energies were within $10 \mathrm{~kJ} \mathrm{~mol}^{-1}$ off the lowest energy configuration. The three types of interionic distances were considered-namely, cation $\cdots$ cation, cation $\cdots$ anion, and anion $\cdots$ anion. For each unique cation and anion, a centre atom of the ion was identified and interionic distances were measured between centres of ions. The B and $\mathrm{N}$ central atoms were taken as the centre of the tetrafluoroborate anion and pyrrolidinium cations, respectively. For the imidazolium cations, the middle point between the two nitrogen atoms of the imidazolium ring was assigned the centre, whereas for the dicyanamide anion the central nitrogen atom was taken as the centre. For pyrrolidinium clusters, the cation $\cdots$ anion distance is longer compared to that in imidazolium.

Analysis of Table I reveals that in general the lower bound of the cation $\cdots$ anion distance in the pyrrolidinium-based clusters is longer by at least $0.8 \AA$ than those in imidazolium clusters. The smaller interionic distances in the imidazoliumbased ILs, mainly due to the absence of steric hindrance, allows for a higher degree of dispersion forces. This trend was also observed in single ion pairs of imidazolium ionic liquids. ${ }^{28}$ The presence of the $\pi^{+}-\pi^{+}$stacking of imidazolium rings also results in shorter cation $\cdots$ cation distances in imidazolium ionic liquids. This is reflected in a similar trend in the anion $\cdots$ anion distances that are 0.7-1.1 $\AA$ shorter in the imidazolium salts compared to those in analogous pyrrolidinium-based ILs. Compared to the previously published optimised structures of single ion pairs of both imidazolium and pyrrolidinium cations, ${ }^{91,92}$ interionic distances in 2 ion-paired clusters tend

TABLE I. Interionic distances (in $\AA$ ) in two ion-paired clusters of $\left[\mathrm{C}_{\mathrm{n}} \mathrm{mim}\right] \mathrm{X}$ and $\left[\mathrm{C}_{\mathrm{n}} \mathrm{mpyr}\right] \mathrm{X}$ ionic liquids $\left[\mathrm{n}=1-4\right.$ and $\mathrm{X}=\mathrm{Cl}^{-}, \mathrm{BF}_{4}{ }^{-}$, and $\mathrm{N}(\mathrm{CN})_{2}{ }^{-}$].

\begin{tabular}{|c|c|c|c|}
\hline Ionic liquid & Cation...Cation & Cation $\cdot$ Anion & Anion $\cdots$ Anion \\
\hline$\left[\mathrm{C}_{\mathrm{n}} \operatorname{mim}\right]\left[\mathrm{BF}_{4}\right]$ & $4.6-5.8$ & $3.1-4.8$ & $4.8-5.9$ \\
\hline$\left[\mathrm{C}_{\mathrm{n}} \operatorname{mim}\right] \mathrm{Cl}$ & $3.2-5.3$ & $3.0-4.6$ & $4.7-7.4$ \\
\hline$\left[\mathrm{C}_{\mathrm{n}} \operatorname{mim}\right]\left[\mathrm{N}(\mathrm{CN})_{2}\right]$ & $3.4-5.1$ & $3.2-6.1$ & $6.1-8.2$ \\
\hline$\left[\mathrm{C}_{\mathrm{n}} \mathrm{mpyr}\right]\left[\mathrm{BF}_{4}\right]$ & $5.2-6.5$ & $3.9-4.9$ & $5.5-6.8$ \\
\hline$\left[\mathrm{C}_{\mathrm{n}} \mathrm{mpyr}\right] \mathrm{Cl}$ & $5.1-5.4$ & $3.8-4.4$ & $5.7-6.0$ \\
\hline$\left[\mathrm{C}_{\mathrm{n}} \mathrm{mpyr}\right]\left[\mathrm{N}(\mathrm{CN})_{2}\right]$ & $5.3-6.5$ & $3.9-5.9$ & $7.2-8.0$ \\
\hline
\end{tabular}

to be longer - in the range of $0.5-1 \AA$ - thus affecting the interplay of fundamental forces. This observation further highlights the importance of considering large-scale clusters and nonequilibrium geometries (in which ions are further removed from the equilibrium) for drawing reliable conclusions for ionic liquids.

\section{Scaling of HF interaction energies}

The MP2 energy is comprised of the HF energy and the contribution from electron correlation. Our new method, SRS-MP2, predicts the latter very well with cc-pVTZ, a relatively small basis set. ${ }^{30}$ However, the HF energy is not yet converged and requires much more expensive basis sets to give comparable errors. This section outlines a new scaling method to allow anyone to correct the HF energy to the complete basis set and was used for the cluster calculations in this work.

It is well known that HF electronic energies converge fast with an increasing basis set for single molecules. In this study, we tested the convergence for interaction energies of two ion-paired clusters. HF interaction energies of the two ionpaired configurations within $10 \mathrm{~kJ} \mathrm{~mol}^{-1}$ for each cation-anion combination were calculated for a series of Dunning's basis sets, non-augmented cc-pVXZ, and augmented aug-cc-pVXZ $(\mathrm{X}=\mathrm{D}, \mathrm{T}$, and $\mathrm{Q})$ with the view of establishing the reliability of smaller basis sets for the prediction of HF interaction energies in larger clusters. These interaction energies were calculated with and without counterpoise corrections developed by Boys and Bernardi. ${ }^{93}$ Overall, 64 two ion-paired configurations were used for further analysis.

Table II shows statistical measures such as mean absolute errors (MAEs), standard deviations (SDs), and maximum absolute errors (Max) for the standard HF interaction energies given per ion pair. HF/aug-cc-pVQZ interaction energies without counterpoise correction were used as the benchmark data. Without counterpoise correction, the errors are large for the double- $\zeta$ basis sets as well as for cc-pVTZ. The maximum errors fall between 20 and $55 \mathrm{~kJ} \mathrm{~mol}^{-1}$. The aug-cc-pVTZ basis set is needed to produce errors below chemical accuracy, with

TABLE II. Error statistics (in $\mathrm{kJ} \mathrm{mol}^{-1}$ ) for standard and scaled HF interaction energies per one ion pair with and without counterpoise corrections. Errors are per one ion pair.

\begin{tabular}{|c|c|c|c|c|c|c|c|c|c|}
\hline \multirow{2}{*}{$\begin{array}{l}\mathrm{CP} \\
\text { correction }\end{array}$} & \multirow{2}{*}{$\begin{array}{l}\text { Basis } \\
\text { set }\end{array}$} & \multicolumn{3}{|c|}{ Standard HF } & \multirow[b]{2}{*}{$\alpha$} & \multirow[b]{2}{*}{$\beta$} & \multicolumn{3}{|c|}{ Scaled HF } \\
\hline & & Max & MAE & $\mathrm{SD}$ & & & Max & MAE & $\mathrm{SD}$ \\
\hline \multirow{5}{*}{ No } & VDZ & 52.1 & 40.1 & 6.4 & 0.874 & -10.913 & 12.6 & 3.9 & 4.7 \\
\hline & VTZ & 20.1 & 14.9 & 3.3 & 0.928 & -12.505 & 3.5 & 1.5 & 1.8 \\
\hline & VQZ & 8.4 & 5.1 & 2.2 & 0.963 & -8.791 & 2.7 & 1.4 & 1.6 \\
\hline & AVDZ & 24.9 & 10.5 & 6.9 & 0.977 & 1.906 & 14.4 & 6.2 & 6.9 \\
\hline & AVTZ & 4.0 & 1.9 & 1.3 & 1.004 & 3.468 & 2.0 & 1.2 & 1.2 \\
\hline \multirow{5}{*}{ Yes } & VDZ & 11.9 & 5.5 & 4.0 & 0.941 & -16.459 & 5.8 & 2.5 & 3.0 \\
\hline & VTZ & 6.2 & 2.6 & 2.6 & 0.967 & -9.789 & 3.7 & 1.8 & 2.1 \\
\hline & VQZ & 2.6 & 1.4 & 1.5 & 0.985 & -5.087 & 2.0 & 1.3 & 1.4 \\
\hline & AVDZ & 1.7 & 0.9 & 0.4 & 1.002 & -0.088 & 0.8 & 0.3 & 0.4 \\
\hline & AVTZ & 1.5 & 0.7 & 0.4 & 0.999 & 1.010 & 0.8 & 0.4 & 0.4 \\
\hline
\end{tabular}




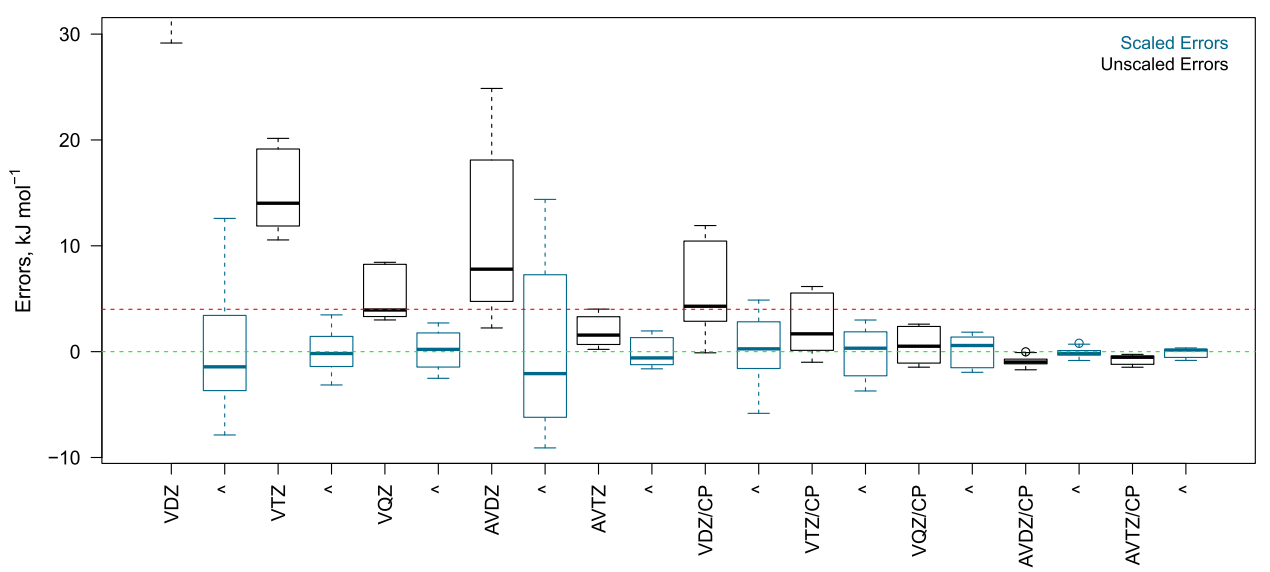

FIG. 3. Errors for 2 IP systems for unscaled (black) and scaled (blue) against cc-pVQZ energies where VDZ represents cc-pVDZ, $A$ is augmentation, and $\mathrm{CP}$ is the counterpoise correction. The green and red dashed lines indicated 0.0 and $4.0 \mathrm{~kJ} \mathrm{~mol}^{-1}$ errors, respectively. the maximum error of as little as $4 \mathrm{~kJ} \mathrm{~mol}^{-1}$. Counterpoise correction (CP) was necessary to reduce the error to below chemical accuracy for the cc-pVTZ basis set. The correction produces excellent results for the augmented basis sets as well as for cc-VTZ and cc-pVQZ.

Counterpoise corrected calculations are very time consuming when larger clusters are considered. The use of augmented basis sets such as aug-cc-pVTZ, even without the counterpoise correction, is not a solution either as these require a significant increase in computational resources and usually show very slow convergence of the HF energy for multi-scale clusters of ionic liquids due to the presence of degenerate molecular orbitals on anions.

The exponential convergence of the HF electronic energy has been well established for systematically improved basis sets such as Dunning's basis sets. ${ }^{94-96}$ In this study, this type of convergence [see Eq. (2)] was adopted to scale HF interaction energies to reproduce the benchmark energies,

$$
E_{\text {pred }}^{I N T}=\alpha \cdot E_{H F}^{I N T}+\beta,
$$

where $E_{\text {pred }}^{I N T}$ is the predicted interaction energy, $E_{H F}^{I N T}$ is the HF interaction energy with smaller basis sets, and $\alpha$ and $\beta$ are the scaling coefficients. The latter were fitted using chisquared minimisation (weighted sum of squared deviations) as implemented in the Imfit package for Python. ${ }^{97}$ The fitted coefficients together with statistical measures are given in Table II. As one can see, a significant improvement has been achieved for non-counterpoise corrected HF interaction energies. For the cc-pVTZ basis set, the maximum error is reduced to below chemical accuracy (see Fig. 3), with the MAE falling below $2 \mathrm{~kJ} \mathrm{~mol}^{-1}$. The fitted scaling coefficients were also applied to the previously studied single ion pairs. Similar errors were observed for non-counterpoise corrected $\mathrm{HF} / \mathrm{cc}-\mathrm{pVTZ}$ interaction energies, with a MAE of $1.8 \mathrm{~kJ} \mathrm{~mol}^{-1}$ and SD of $1.7 \mathrm{~kJ} \mathrm{~mol}^{-1}$ (for more details, see the supplementary material). Further in the text, scaled HF/cc-pVTZ interaction energies were used for the selected 2 ion-paired configurations.

\section{TOTAL ELECTRONIC ENERGY VS. INTERACTION ENERGY}

In this study, total electronic energy was used as the criterion to select the most stable 2 ion-paired configurations.
There are two other criteria commonly used in the field of theoretical chemistry-namely, binding energy and interaction energy. Binding energy, $\mathrm{E}_{\mathrm{BIND}}$, is defined as the energy difference between that of a cluster, $E_{\text {cluster }}$, and the sum of energies of individual ions, $E_{i o n}^{i}$, taken in their minimum energy geometry [see Eq. (3)]. In order to obtain the latter, individual ions need to be geometry optimized separately,

$$
E_{B I N D}=E_{\text {cluster }}-\sum_{i} E_{\text {ion }}^{i}(\min )+\Delta Z P V E,
$$

where min indicates that the ion is taken in its lowest energy geometry and $\triangle Z P V E$ is the difference in zero-point vibration energies of the cluster and constituting ions. In two ion paired clusters, it was expected to contribute within $5 \mathrm{~kJ} \mathrm{~mol}^{-1}$ on average per mole of ionic liquid (i.e., calculated per ion pair). For example, $\left[\mathrm{C}_{1} \mathrm{mim}\right]\left[\mathrm{BF}_{4}\right],\left[\mathrm{C}_{3} \mathrm{mim}\right] \mathrm{Cl}$, and $\left[\mathrm{C}_{1}\right.$ mpyr $]\left[\mathrm{N}(\mathrm{CN})_{2}\right]$ have the values of $\triangle Z P V E$ of $4.7,1.9$, and $5.3 \mathrm{~kJ} \mathrm{~mol}^{-1}$, respectively. Vibrational frequency calculations are very time consuming as these require computation of the Hessian matrix. Although the effect of vibrational frequency contribution is not negligible for some ionic liquids, it is not computationally feasible to perform this type of calculations for large-scale clusters on the routine basis.

It is usually customary to include counterpoise correction to account for molecular orbital overlap due to an incomplete basis set. The use of energies of ions in their lowest energy geometry introduces a reference point and allows for the calculation of the energy gain in the formation of the cluster. This energy gain is usually attributed to intermolecular fundamental forces that ensure the stability of the cluster. If the counterpoise correction is not included, especially for wavefunction-based methods, binding energies become significantly over-estimated up to $20 \mathrm{~kJ} \mathrm{~mol}^{-1}$ in some cases. ${ }^{92}$ This effect has been shown to drastically increase with inclusion of more ions in the system. ${ }^{80}$ Due to the constant reference point for individual ions, the use of binding energy as a criterion to determine thermodynamically stable structures becomes similar to total electronic energy, provided both are corrected for basis set superposition error. For ionic liquids, individual ions represent an unrealistic reference point as it is well known that these ions cannot exist on their own without either the counter-ions present or a stabilising medium. Nonetheless, binding energy directly relates to total interaction energy 
with the difference being the reference point for the cation and anion.

Interaction energy, $E_{I N T}$, is different from both total electronic energy and binding energy as the energy of individual ions is calculated using the geometry these adopt in the cluster as shown in the following figure:

$$
E_{I N T}=E_{\text {cluster }}-\sum_{i} E_{\text {ion }}^{i}(\text { cluster }),
$$

where the ions are in the geometry they adopt in the cluster. It is important to account for counterpoise corrections to make interaction energy more reliable and realistic.

The main difference between binding and interaction energies lies in the deformation energy that is associated with an increase in the energy of individual ions due to the geometry deformation that each ion undergoes in an ionic cluster. This deformation occurs as a result of the presence of intermolecular interactions. For example, hydrogen boding can result in a stretch of the $\mathrm{C}-\mathrm{H}$ and $\mathrm{N}-\mathrm{H}$ bonds, ${ }^{98}$ whereas phosphonium cations are known to have greater flexibility about the phosphorus centre due to the larger range of allowed bond angles. ${ }^{99}$ To this end, interaction energy quantifies the pure energy gain as a result of intermolecular interactions, whereas binding energy also includes the geometry and zero-point vibrational energy effect for constituting ions. It must be pointed out that total electronic energy already includes deformation energy of ions, which is more likely to be the larger contributor of the two.

Out of all the criteria, binding energies are much more computationally demanding as these require the calculation of the Hessian to confirm the minimum on the potential energy surface and cannot be applied to non-equilibrium geometries. It is computationally infeasible to perform Hessian calculations for multi-scale clusters of ionic liquids beyond 4 ion pairs and therefore this criterion is hardly used for studying intermolecular complexes. ${ }^{72}$ In the field of molecular dynamics simulations, it is common to minimise Gibbs free energy to locate the most stable structure of a condensed system at a given temperature. ${ }^{100-103}$ For quantum chemical calculations of multi-scale clusters of ionic liquids, interaction energy has been widely used to analyze their thermodynamic stability, thus excluding the deformation energy. Deformation energy becomes exceedingly important when increasing the number of ions in the cluster as well as when investigating complex ions, such as those with long alkyl chains or polar groups with strong hydrogen bonding ability.

In this study, both criteria, interaction energy and total electronic energy (further in the text referred to as total energy), are contrasted for the selection of energetically stable configurations of two ion-paired clusters, with total energy serving as the benchmark. The same lowest energy configurations could only be located in 14 out of 24 studied systems (in approximately $58 \%$ of systems) with interaction energy as a criterion. This has been achieved for the clusters of $\left[\mathrm{C}_{\mathrm{n}} \operatorname{mim}\right] \mathrm{X}$ $\left(\mathrm{X}=\mathrm{BF}_{4}{ }^{-}\right.$and $\left.\mathrm{N}(\mathrm{CN})_{2}{ }^{-}\right),\left[\mathrm{C}_{\mathrm{n}} \mathrm{mpyr}\right] \mathrm{Cl},\left[\mathrm{C}_{2} \mathrm{mpyr}\right]\left[\mathrm{BF}_{4}\right]$, and $\left[\mathrm{C}_{3}\right.$ mpyr $]\left[\mathrm{N}(\mathrm{CN})_{2}\right](\mathrm{n}=1-4)$. Interaction energy fails to locate the lowest energy structures for imidazolium chlorides and the majority of pyrrolidinium ILs coupled with the tetrafluoroborate and dicyanamide anions (see Fig. 2). In all the 24 systems, the criterion still identified the lowest energy configuration by total energy within $10 \mathrm{~kJ} \mathrm{~mol}^{-1}$. In 13 of these systems (in approximately $54 \%$ of systems), the order of lower energy configurations within $10 \mathrm{~kJ} \mathrm{~mol}^{-1}$ by interaction energy does not correspond to that by total energy. Some typical examples are shown in Fig. 4. In $\left[\mathrm{C}_{4} \mathrm{mpyr}\right]\left[\mathrm{BF}_{4}\right]$, the third lowest energy configuration was not identified by interaction energy, placing it almost $15 \mathrm{~kJ} \mathrm{~mol}^{-1}$ above in energy, whereas an opposite trend was observed for $\left[\mathrm{C}_{3} \mathrm{mpyr}\right] \mathrm{Cl}$ and $\left[\mathrm{C}_{2} \mathrm{mim}\right]\left[\mathrm{N}(\mathrm{CN})_{2}\right]$. The use of interaction energy locates a couple of configurations within $10 \mathrm{~kJ} \mathrm{~mol}^{-1}$, whereas their total energies are at least $15 \mathrm{~kJ} \mathrm{~mol}^{-1}$ higher in energy than the lowest energy configuration (see Fig. 4). These findings indicate that a configuration with the strongest interaction energy does not necessarily possess the lowest total energy. The latter represents a more realistic result from the conceptual point of view and when compared with experiment.

Examples of the difference between relative interaction energies and relative total energies are shown in Figs. 4(a) and 4(b). Configurations within $10 \mathrm{~kJ} \mathrm{~mol}^{-1}$ are labeled and can be found in Fig. 2. The differences between relative total energy and relative interaction energy fall consistently on the absolute scale between 3.3 (for $\left[\mathrm{C}_{\mathrm{n}} \mathrm{mpyr}\right]\left[\mathrm{BF}_{4}\right]$ ) and $5.4 \mathrm{~kJ} \mathrm{~mol}^{-1}$ (for $\left[\mathrm{C}_{\mathrm{n}} \mathrm{mim}\right] \mathrm{Cl}$ ) on average (see Table III) with no particular trend with respect to the ionic liquid type. The differences can be equally positive and negative as demonstrated by low values of mean yet can be significant with a maximum difference of $31.2 \mathrm{~kJ} \mathrm{~mol}^{-1}$.

To this end, interaction energy does not appear to be a reliable criterion for determining not only the lowest energy configuration but also the order of configurations within $10 \mathrm{~kJ} \mathrm{~mol}^{-1}$. In $58 \%$ of the 2 ion paired systems studied, interaction energy could not locate the lowest energy configuration, and in $54 \%$ of the systems the order of lower energy configuration was not correctly identified, with some higher energy structures having interaction energy within $10 \mathrm{~kJ} \mathrm{~mol}^{-1}$.

The two ion pair deformation energies in Table IV show that the cations and the $\mathrm{BF}_{4}^{-}$anion contribute significantly through the deformation of their covalent bonds. Although chloride cannot deform, its ability to form strong electrostatic interactions has a significant effect on the cation which becomes more destabilised in its presence when compared to either $\mathrm{BF}_{4}{ }^{-}$or $\mathrm{N}(\mathrm{CN})_{2}{ }^{-}$. The imidazolium cations tend to undergo a larger deformation than the pyrrolidinium ones except when dicyanamide is involved. The dicyanamide anion preferentially interacts through both of the terminal nitrogens, which can be easier accommodated by the imidazolium ring. Since the pyrrolidinium ring lacks this feature, in order to allow for unobstructed access to the nitrogen centres and hence an increase interaction energy, it requires to move the alkyl chains out of the way, thus resulting in puckering of the nitrogen centre. Imidazolium coupled with tetrafluoroborate and dicyanamide gives similar values for the deformation energy, further highlighting the ability of this cation to be easily polarised in response to changes in environment without a geometric change. As deformation energies are the result of the re-arrangement of internal molecular structure to 


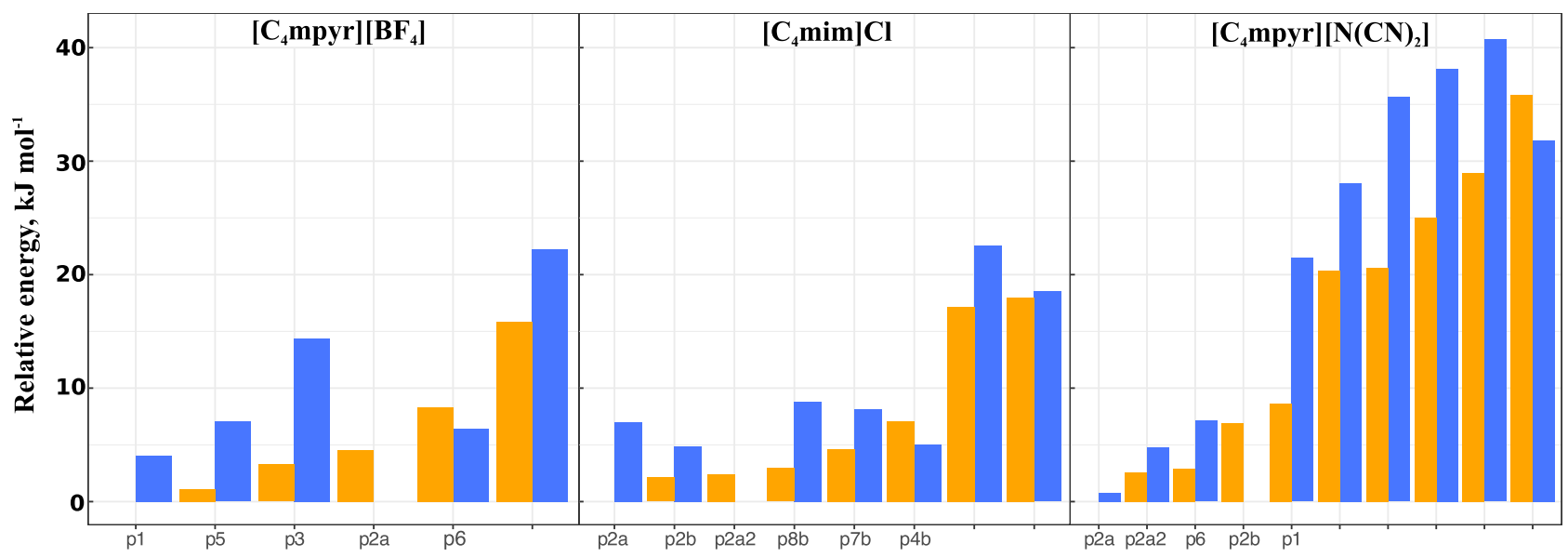

(a)

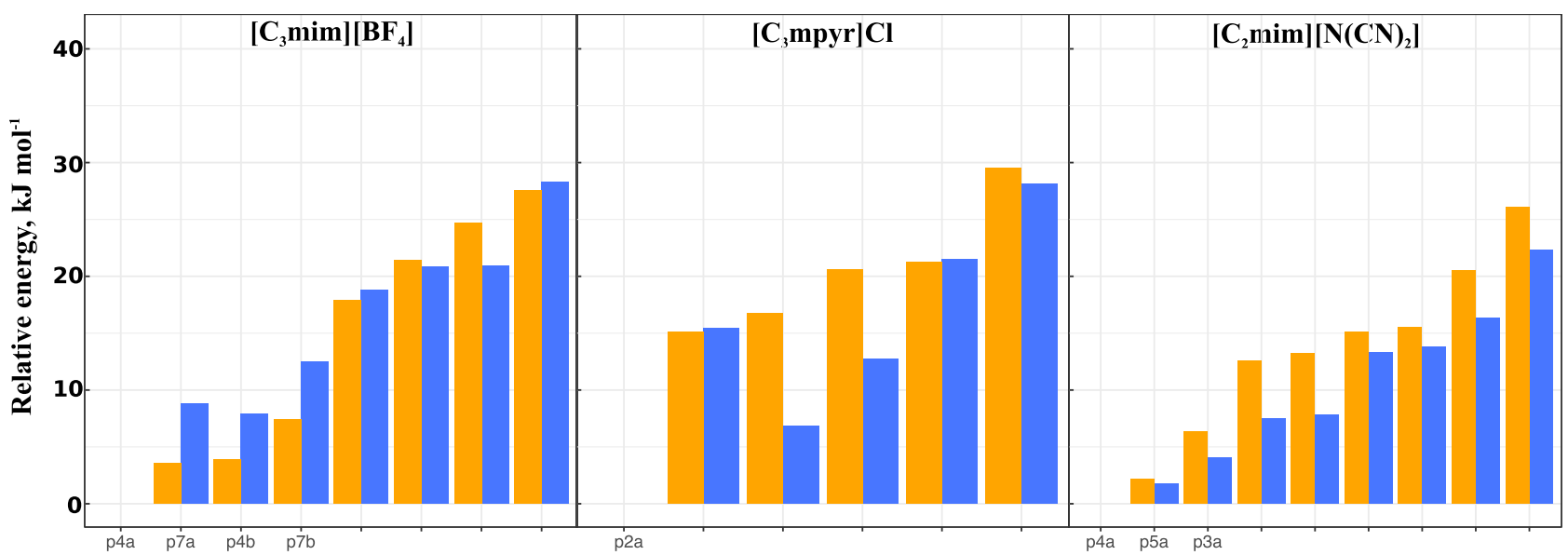

(b)

FIG. 4. Comparison of relative interaction energy (blue) and relative total energy (orange) of configurations optimized for 2 ion-paired clusters of (a) $\left[\mathrm{C}_{4} \mathrm{mpyr}\right]\left[\mathrm{BF}_{4}\right],\left[\mathrm{C}_{4} \mathrm{mim}\right] \mathrm{Cl}$, and $\left[\mathrm{C}_{4} \mathrm{mpyr}\right]\left[\mathrm{N}(\mathrm{CN})_{2}\right]$ and $(\mathrm{b})\left[\mathrm{C}_{3} \mathrm{mim}\right]\left[\mathrm{BF}_{4}\right],\left[\mathrm{C}_{3} \mathrm{mpyr}\right] \mathrm{Cl}$, and $\left[\mathrm{C}_{2} \mathrm{mim}\right]\left[\mathrm{N}(\mathrm{CN})_{2}\right]$.

enhance interaction and are quantitatively larger than chemical accuracy, it is unquestioningly important to consider them to accurately represent the bulk material.

\section{Dispersion forces and ratio}

The probability of encountering energy state $i$ out of all possible states $I$ is given by

$$
p_{i}=\frac{e^{-\mathrm{E}_{i}^{\mathrm{tot}} / k_{B} T}}{\sum_{j}^{I} e^{-\mathrm{E}_{j}^{\mathrm{tot}} / k_{B} T}},
$$

TABLE III. Error statistics (in $\mathrm{kJ} \mathrm{mol}^{-1}$ ) for the difference between relative interaction energy and relative total energy.

\begin{tabular}{lccrr}
\hline \hline Ionic liquids & No. of systems & MAE & Mean & Max \\
\hline$\left[\mathrm{C}_{\mathrm{n}}\right.$ mim $]\left[\mathrm{BF}_{4}\right]$ & 34 & 3.4 & -0.6 & 8.3 \\
{$\left[\mathrm{C}_{\mathrm{n}} \mathrm{mim}\right] \mathrm{Cl}$} & 34 & 5.4 & 1.7 & 31.2 \\
{$\left[\mathrm{C}_{\mathrm{n}} \mathrm{mim}\right]\left[\mathrm{N}(\mathrm{CN})_{2}\right]$} & 29 & 3.7 & 3.6 & 10.8 \\
{$\left[\mathrm{C}_{\mathrm{n}} \mathrm{mpyr}\right][\mathrm{BF}$} & 27 & 3.3 & -0.5 & -11.1 \\
{$\left[\mathrm{C}_{\mathrm{n}} \mathrm{mpyr}\right] \mathrm{Cl}$} & 29 & 3.9 & 3.8 & 11.3 \\
{$\left[\mathrm{C}_{\mathrm{n}} \mathrm{mpyr}\right]\left[\mathrm{N}(\mathrm{CN})_{2}\right]$} & 41 & 5.1 & 0.4 & 18.4 \\
\hline \hline
\end{tabular}

where $k_{B}$ is the Boltzmann constant, $T$ is the temperature, and the Boltzmann distribution is dependent on the total energy of the state, $E^{\text {tot }}$. A Boltzmann averaged property is therefore the sum of each state multiplied by its probability. For example, the interaction dispersion energy weighted by the Boltzmann distribution is

$$
E_{I N T}^{\text {disp }}=\Sigma_{i}^{I}\left(p_{i} \times E_{I N T, i}^{d i s p}\right) .
$$

The ranges of ratios and interaction dispersion energy determined via Eqs. (5) and (6) for the two ion pairs are given

TABLE IV. Deformation energies $\left(\mathrm{kJ} \mathrm{mol}^{-1}\right)$ averaged for the cations and

\begin{tabular}{|c|c|c|c|c|c|c|}
\hline \multirow[b]{2}{*}{ Ionic liquids } & \multicolumn{3}{|c|}{ Cation } & \multicolumn{3}{|c|}{ Anion } \\
\hline & $\operatorname{Max}$ & Mean & SD & Max & Mean & SD \\
\hline$\left[\mathrm{C}_{\mathrm{n}} \operatorname{mim}\right]\left[\mathrm{BF}_{4}\right]$ & 9.1 & 6.6 & 1.4 & 6.8 & 4.7 & 1.1 \\
\hline$\left[\mathrm{C}_{\mathrm{n}} \operatorname{mim}\right] \mathrm{Cl}$ & 26.7 & 12.6 & 3.9 & 0.0 & 0.0 & 0.0 \\
\hline$\left[\mathrm{C}_{\mathrm{n}} \operatorname{mim}\right]\left[\mathrm{N}(\mathrm{CN})_{2}\right]$ & 9.6 & 6.0 & 1.7 & 4.8 & 2.7 & 1.2 \\
\hline$\left[\mathrm{C}_{\mathrm{n}} \mathrm{mpyr}\right]\left[\mathrm{BF}_{4}\right]$ & 12.1 & 5.6 & 2.6 & 6.3 & 4.5 & 1.0 \\
\hline$\left[\mathrm{C}_{\mathrm{n}} \mathrm{mpyr}\right] \mathrm{Cl}$ & 13.3 & 8.7 & 2.1 & 0.0 & 0.0 & 0.0 \\
\hline$\left[\mathrm{C}_{\mathrm{n}} \mathrm{mpyr}\right]\left[\mathrm{N}(\mathrm{CN})_{2}\right]$ & 16.1 & 7.6 & 3.7 & 4.9 & 3.3 & 0.8 \\
\hline
\end{tabular}
anions of each configuration. 
TABLE V. Ratio and dispersion energy per ion pair $\left(\mathrm{kJmol}^{-1}\right)$ ranges for 2 ions paired systems and 1 ion pair model.

\begin{tabular}{lccccc}
\hline \hline & Ratio 2 IP & Ratio 1 IP & $\mathrm{E}_{\text {Disp }}$ 2 IP & $\mathrm{E}_{\text {Disp }} 1 \mathrm{IP}^{28}$ \\
\hline$\left[\mathrm{C}_{\mathrm{n}} \mathrm{mim}\right]\left[\mathrm{BF}_{4}\right]$ & $5.8-7.3$ & $10.1-11.0$ & -63.3 to -52.2 & -37.4 to -34.5 \\
{$\left[\mathrm{C}_{\mathrm{n}} \mathrm{mim}\right] \mathrm{Cl}$} & $5.4-6.4$ & $9.0-9.8$ & -72.9 to -63.1 & -45.6 to -42.5 \\
{$\left[\mathrm{C}_{\mathrm{n}} \mathrm{mim}\right]\left[\mathrm{N}(\mathrm{CN})_{2}\right]$} & $3.4-4.2$ & $6.5-7.0$ & -95.3 to -82.2 & -32.0 to -30.8 \\
{$\left[\mathrm{C}_{\mathrm{n}} \mathrm{mpyr}\right][\mathrm{BF}$} & -6.1 & $5.1-6.5$ & $11.4-12.0$ & -69.2 to -57.2 & -56.4 to -50.7 \\
{$\left[\mathrm{C}_{\mathrm{n}} \mathrm{mpyr}\right] \mathrm{Cl}$} & $5.5-6.8$ & $10.7-11.3$ & -71.8 to -60.2 & -36.5 to -35.0 \\
{$\left[\mathrm{C}_{\mathrm{n}} \mathrm{mpyr}\right]\left[\mathrm{N}(\mathrm{CN})_{2}\right]$} & $3.6-5.5$ & $8.7-9.2$ & -89.8 to -63.0 & -39.7 to -38.0 \\
\hline \hline
\end{tabular}

in Table $\mathrm{V}$ as well as the previously published 1 ion pair data for comparison. ${ }^{28}$ The previously published approach has been improved in three ways. First, previously the ion pair model energies were calculated with a different method, symmetry-adapted perturbation theory, which has a different definition for dispersion energy than post-HF methods such as SRS-MP2 as the former accounts for exchange component of dispersion. Second, the Boltzmann distribution used to weight the one ion pair data was based on the interaction energy of the system, in contrast to the two ion pairs which were weighted based on their total electronic energy. Third, the previously published correlations only included ionic liquids whose melting point continued to decrease with increasing alkyl chain length. This was done to ensure that interactions among like-charged ions were not the main contributor to thermodynamic and transport properties. In the current work, this limitation has been lifted, with all ionic liquids for which experimental data have been published being included in the analysis.

Analysis of Table $\mathrm{V}$ reveals that, on average, the ratio range for 2 IP clusters is almost half that of 1 IP systems. While two ion pair clusters experience an increase from both electrostatics and dispersion forces, the electrostatic interactions do not increase as drastically therefore causing the ratio to reduce. The slow increase in electrostatic forces can be explained by the presence of both attractive and repulsive interactions, whereas the dispersion forces between ions are by definition always attractive regardless of their charge. For example, the average $\mathrm{HF}$ interaction energy of the $2 \mathrm{IP}\left[\mathrm{C}_{1} \mathrm{mim}\right]\left[\mathrm{BF}_{4}\right]$ structures $\left(-590.0 \mathrm{~kJ} \mathrm{~mol}^{-1}\right)$ is $\sim 1.7$ times that of the $1 \mathrm{IP}$ systems $\left(-342.2 \mathrm{~kJ} \mathrm{~mol}^{-1}\right)$. The average dispersion interaction energy in $\left[\mathrm{C}_{1} \mathrm{mim}\right]\left[\mathrm{BF}_{4}\right]$ structures increases by a factor of 3.5 from $1 \mathrm{IP}\left(-35.1 \mathrm{~kJ} \mathrm{~mol}^{-1}\right)$ to $2 \mathrm{IPs}\left(-124.6 \mathrm{~kJ} \mathrm{~mol}^{-1}\right)$.

With an increasing number of ions, the potential energy surface is expected to flatten out due to the increased contribution from dispersion forces. The latter is demonstrated in a wider spread of the dispersion component from $3.0 \mathrm{~kJ} \mathrm{~mol}^{-1}$ for single ion pairs to $11.5 \mathrm{~kJ} \mathrm{~mol}^{-1}$ for 2 ion-paired systems. In addition, the inclusion of same-ion interactions impacts the distribution of the dispersion component to interaction energy for all the ILs studied increasing from $25.6 \mathrm{~kJ} \mathrm{~mol}^{-1}$ on average for 1 IPs to $37.6 \mathrm{~kJ} \mathrm{~mol}^{-1}$ on average for 2 IPs. In some cases, such as $\left[\mathrm{C}_{\mathrm{n}} \mathrm{mpyr}\right]\left[\mathrm{N}(\mathrm{CN})_{2}\right]$ and $\left[\mathrm{C}_{\mathrm{n}} \operatorname{mim}\right]\left[\mathrm{N}(\mathrm{CN})_{2}\right]$, the dispersion component increases nearly three-fold. This also explains wider ranges for the ratio in the 2 IP systems. It is important to note that for two ion-paired systems the ratio becomes less dependent on the cation-anion combination, falling within a small range of 3.4-5.5 (compared to the range of 6.5-12.0 for 1 IP models). As has been showcased for ionic liquid clusters of varying size from 4 to 32 ion pairs, ${ }^{30}$ dispersion energy continues to grow with increasing cluster size and therefore the ratio might not have converged for two ion-paired systems. More studies on larger clusters are required to confirm whether the distribution of the ratio becomes even narrower regardless of the ionic liquid type.

Behaviour of the dispersion component in 2 IPs suggests that the anion has a larger effect than the type of cation. The dispersion component increases in the series of $\mathrm{BF}_{4}{ }^{-}$to $\mathrm{Cl}^{-}$ to $\mathrm{N}(\mathrm{CN})_{2}{ }^{-}$for both imidazolium- and pyrrolidinium-based cations. Contrary to this trend, the ratio is affected inversely in the same series, with the outlier being $\left[\mathrm{C}_{\mathrm{n}} \mathrm{mpyr}\right] \mathrm{Cl}$, whose ratio range is larger than that of $\left[\mathrm{C}_{\mathrm{n}} \mathrm{mpyr}\right]\left[\mathrm{BF}_{4}\right]$. In the former, the electrostatic and induction energies appear to have the largest contribution to interaction energy out of the ionic liquids studied. This trend is attributed to the tight alternative packing arrangement (see Table I).

In general, the ratio decreases with increasing cluster size, with the exception of $\left[\mathrm{C}_{\mathrm{n}} \mathrm{mim}\right]\left[\mathrm{BF}_{4}\right]$ and $\left[\mathrm{C}_{\mathrm{n}} \mathrm{mpyr}\right]\left[\mathrm{N}(\mathrm{CN})_{2}\right]$ where $n$ increases from 3 to 4 . The decrease in the ratio going from $n$-propyl to $n$-butyl when combined with the same anion and cation is small (maximum of 0.5) compared to the distribution range of the ratio. The original hypothesis that the ratio correlates with melting point suggests that the trend in the ratio should follow that of melting point in order to produce good correlations. For some ionic liquids, the ratio continues to decrease, whereas the corresponding melting point increases. An example of this is $\left[\mathrm{C}_{3} \mathrm{mim}\right]\left[\mathrm{BF}_{4}\right]$ and $\left[\mathrm{C}_{4} \mathrm{mim}\right]\left[\mathrm{BF}_{4}\right]$, where the increase in melting point from 333 to $342 \mathrm{~K}$ is accompanied by a slight decrease in the ratio from 5.7 to 5.4. This suggests that larger clusters might be needed to produce correlations that can be used to predict melting points of novel ionic liquids.

The relative contribution of dispersion to interaction energy is defined as follows:

$$
E_{I N T}^{\text {disp }}=E_{\text {cluster }}^{\text {disp }}-\sum_{i} E_{\text {ion }}^{i, i o n} .
$$

The relative dispersion for 2 ion-paired systems is plotted against the interaction energy in Fig. 5. The figure also illustrates the number of low energy structures (within $20 \mathrm{~kJ} \mathrm{~mol}^{-1}$ ) for each system and how it follows no particular trend. For the $\mathrm{BF}_{4}^{-}$and $\mathrm{Cl}^{-}$anions, the relative dispersion is comparable regardless of the alkyl chain length ranging from $12.0 \%$ to $16.2 \%$ for imidazolium-based ILs and $12.3 \%$ to $15.7 \%$ for pyrrolidinium-based ionic liquids. The importance of the dispersion component of interaction energy is most clearly demonstrated in the $\mathrm{N}(\mathrm{CN}){ }_{2}{ }^{-}$clusters. The $\mathrm{N}(\mathrm{CN})_{2}{ }^{-}$systems exhibit a greater contribution from dispersion due to its delocalised structure falling in the range of $-110.9\left(\mathrm{C}_{1} \mathrm{mpyr}^{+}\right)$and $-193.2\left(\mathrm{C}_{4} \mathrm{mim}^{+}\right) \mathrm{kJ} \mathrm{mol}^{-1}$ which is up to $\sim 20 \%$ of the interaction energy. This non-negligible component is expected to continue to increase disproportionately with the interaction energy in larger-scale clusters, i.e., the percentage of dispersion in the interaction energy will increase. Larger clusters will need to be investigated until it is seen that the dispersion 


\section{Cation $-\mathrm{C}_{1} \mathrm{mim}^{+} \rightarrow \mathrm{C}_{1} \mathrm{mpyr}^{+}$}
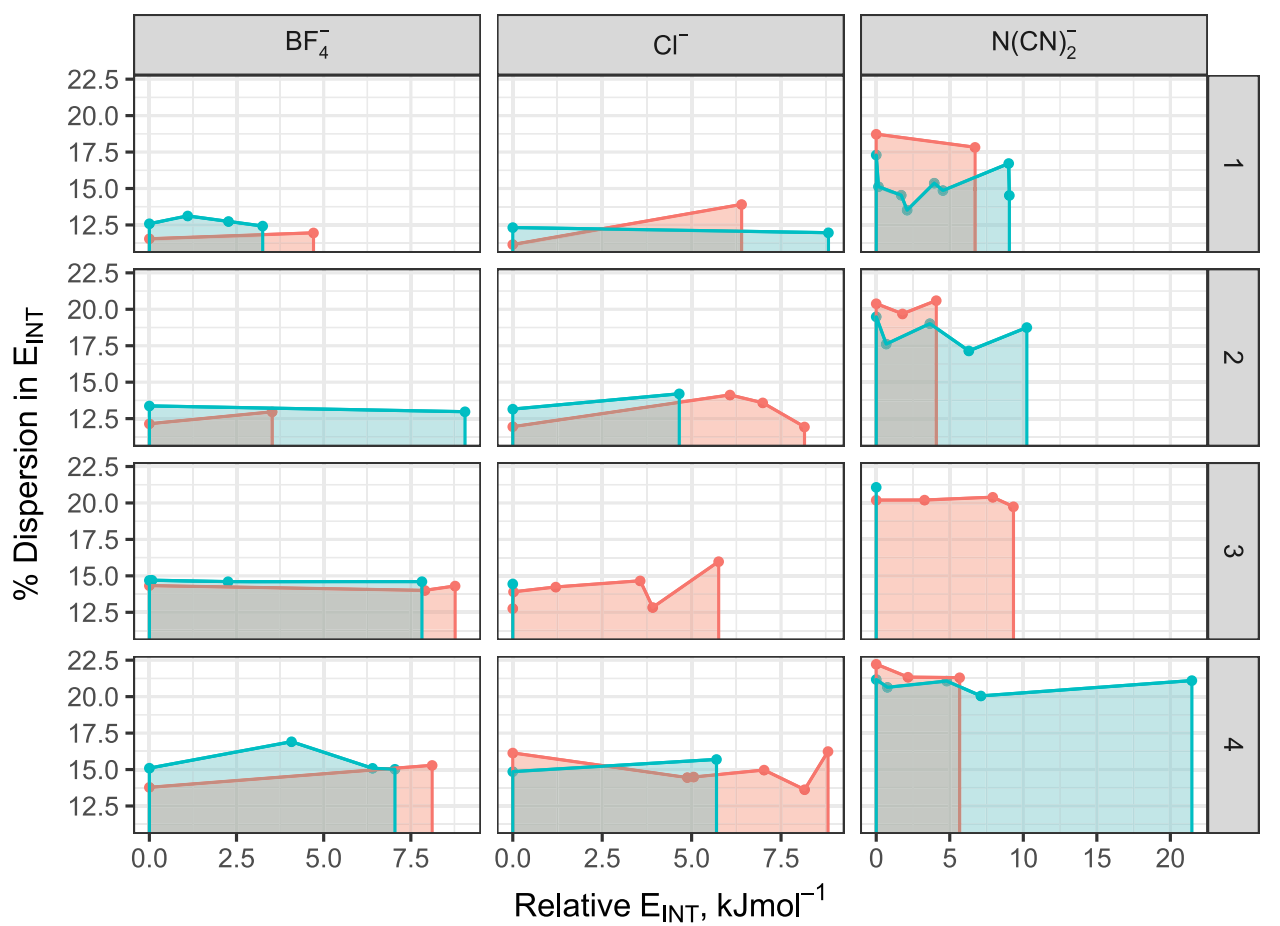

FIG. 5. The relative dispersion (in \%) against relative interaction energy compared in imidazolium- and pyrrolidinium-based ionic liquids for the different anions (columns) and alkyl chain lengths (rows) of low energy configurations. component has converged with cluster size as a proportion of interaction energy.

\section{Correlation of the ratio with melting point}

Here, an attempt to correlate the ratio of interaction energy to its dispersion component observed in clusters of 2 IPs is presented. In our previous work, the same ratio could not be used to predict melting points of ionic liquids when applied to single ion pairs. This conclusion is not surprising since single ion pairs do not account for many-body effects present in the bulk of ionic liquids. It is informative to investigate whether the inclusion of 2 ion pairs in a cluster would result in better trends. It has to be pointed out that the prediction of melting point represents one of the most challenging tasks that is yet to be solved. The results below by no means achieve this goal. On the other hand, they clearly indicate that the ratio is a valid concept and shows promise towards the development of a methodology for the prediction of melting points using the cluster approach.

Figure 6 and Table VI present the established correlations between the ratio and melting point. It was found that the imidazolium tetrafluoroborate ionic liquids formed their own correlation to the remaining ionic liquids and were thus treated separately. It has to be noted that the melting point correlations do not include the data for $\left[\mathrm{C}_{3} \operatorname{mim}\right]\left[\mathrm{N}(\mathrm{CN})_{2}\right]$ and $\left[\mathrm{C}_{2} \mathrm{mpyr}\right] \mathrm{Cl}$ as melting points for these ionic liquids have not been published. Apart from $\left[\mathrm{C}_{n} \mathrm{mim}\right]\left[\mathrm{BF}_{4}\right]$, the remaining ionic liquids were found to fall in a similar range to allow for a general correlation to be established (see Fig. 6). This is a significant improvement in its own right on the previously established correlations for single ion pair models.
In general, the established correlation (see Table VI) allows for the prediction of the melting point of the studied ionic liquids within $54 \mathrm{~K}$ on average, which is comparable to the accuracy of currently used force fields. ${ }^{104-106}$ The melting points span from 202 to $613 \mathrm{~K}$, a range of $411 \mathrm{~K}$. The lowest MAEs as well as standard deviations of $21.3 \mathrm{~K}$ on average were found for dicyanamide-based ionic liquids. The delocalized dicyanamide anion with multiple interaction sites appears to favour alternating charge stacking, which might already be accounted well in smaller-sized clusters.

The worst performing systems are the $\left[\mathrm{C}_{\mathrm{n}} \mathrm{mpyr}\right]\left[\mathrm{BF}_{4}\right]$ ionic liquids, whose collective standard deviation is $88.4 \mathrm{~K}$ which is over $35 \mathrm{~K}$ greater than the standard deviations of the other ionic liquids. The most plausible explanation lies in the fact that the $\left[\mathrm{C}_{1} \mathrm{mpyr}\right]\left[\mathrm{BF}_{4}\right]$ and $\left[\mathrm{C}_{2} \mathrm{mpyr}\right]\left[\mathrm{BF}_{4}\right]$ systems form plastic crystals that undergo a few solid-solid transitions prior

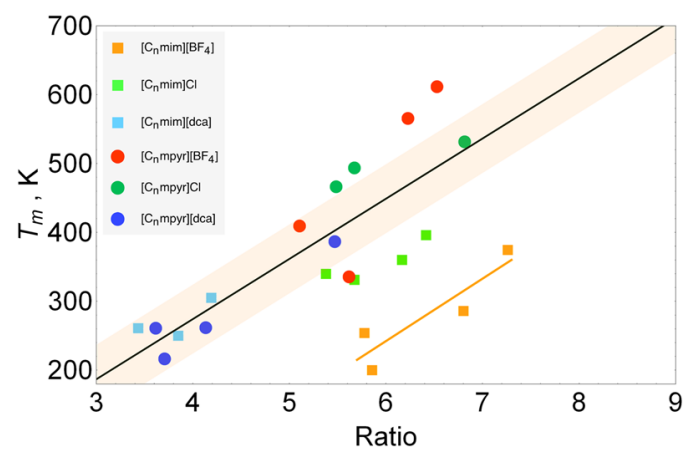

FIG. 6. Correlation of the ratio with experimental melting points with one general correlation (black) which includes all ionic liquids except for $\left[\mathrm{C}_{\mathrm{n}} \mathrm{mim}\right]\left[\mathrm{BF}_{4}\right]$ whose correlation is depicted by an orange line. The region highlighted about the general trend shows $\pm 50 \mathrm{~K}$. 
TABLE VI. Melting point correlations with correlation statistics including the mean absolute error (MAE), standard deviation (SD), and maximum error (Max). All data are given in $\mathrm{K}$.

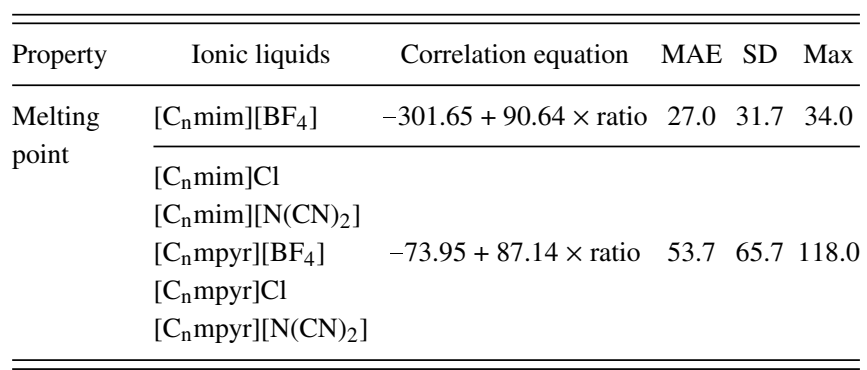

to melting. ${ }^{107-112}$ These transitions are caused by rotation of ions around their internal axis of symmetry, which results in the entropic penalty. As a result, the latter is excluded from the entropy of fusion, thus resulting in higher melting points for this type of compounds. The $\left[\mathrm{C}_{\mathrm{n}} \mathrm{mim}\right] \mathrm{Cl}$ ionic liquids have the second highest MAE of $82.2 \mathrm{~K}$ and an SD of $20.6 \mathrm{~K}$. Out of all imidazolium-based ionic liquids this series was the only to exhibit the $\pi^{+}-\pi^{+}$stacking of imidazolium rings in the lowest energy geometries. This suggests that the bulk structure might not be modeled properly with the 2 ion pair model and larger-scale clusters are needed to establish a reliable trend in the ratio of interaction energy to its dispersion component. It is not well understood why the $\left[\mathrm{C}_{\mathrm{n}} \mathrm{mim}\right]\left[\mathrm{BF}_{4}\right]$ ionic liquids form their own trend that is separate from the rest of ionic liquids. This observation might be attributed to slow convergence of the dispersion component with increasing cluster size.

The current findings illustrate a greater role of the anion compared to the cation in determining the melting point of ionic liquids. The ratio correctly captures the relationship between the dispersion component and melting point for more diffuse anions such as dicyanamide. This might be also attributed to slower convergence of the ratio for more spherical anions such as tetrafluoroborates and chloride. This hypothesis needs to be tested on larger clusters for these anions. To this end, a significant improvement over the single ion pair model has been achieved, with the average error of $54 \mathrm{~K}$ suggesting that more accurate correlation is most likely possible for larger-sized ionic liquid clusters.

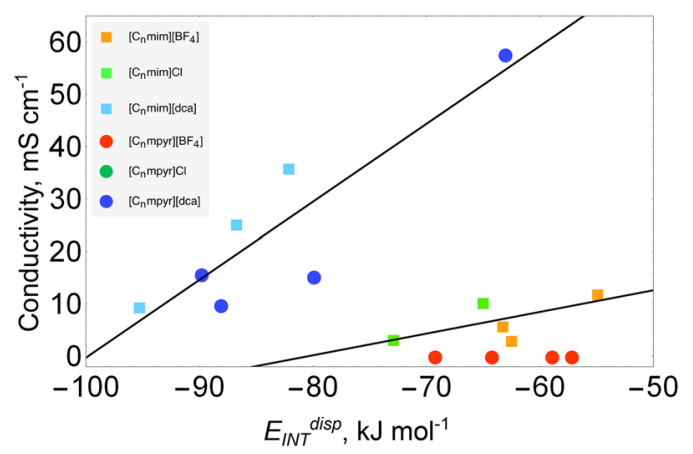

FIG. 7. Correlation of the dispersion interaction energy with experimental conductivity with two correlations (black lines). One encapsulates the $\mathrm{N}(\mathrm{CN})^{-}$ systems and the other is for imidazolium with $\mathrm{BF}_{4}{ }^{-}$and chloride.
TABLE VII. Conductivity correlations with correlation statistics in $\mathrm{mS}$ $\mathrm{cm}^{-1}$.

\begin{tabular}{lccccc}
\hline \hline Property & \multicolumn{1}{c}{ Ionic liquids } & Correlation & & MAE SD Max \\
\hline Conductivity & {$\left[\mathrm{C}_{\mathrm{n}} \mathrm{mim}\right]\left[\mathrm{BF}_{4}\right]$} & $33.37+0.41 \times \mathrm{E}_{\mathrm{INT}}$ disp & 2.2 & 3.1 & 4.6 \\
& {$\left[\mathrm{C}_{\mathrm{n}} \mathrm{mim}\right] \mathrm{Cl}$} & & & & \\
& {$\left[\mathrm{C}_{\mathrm{n}} \mathrm{mim}\right]\left[\mathrm{N}(\mathrm{CN})_{2}\right]$} & $147.58+1.48 \times \mathrm{E}_{\mathrm{INT}}{ }^{\text {disp }}$ & 6.6 & 8.4 & 14.0 \\
{$\left[\mathrm{C}_{\mathrm{n}} \mathrm{mpyr}\right]\left[\mathrm{N}(\mathrm{CN})_{2}\right]$} & & & & \\
\hline \hline
\end{tabular}

\section{Correlation of dispersion component with conductivity}

The conductivity correlations shown in Fig. 7 and Table VII do not include points for $\left[\mathrm{C}_{1} \mathrm{mim}\right]\left[\mathrm{BF}_{4}\right],\left[\mathrm{C}_{1} \mathrm{mim}\right] \mathrm{Cl}$, $\left[\mathrm{C}_{3} \mathrm{mim}\right] \mathrm{Cl},\left[\mathrm{C}_{3} \mathrm{mim}\right]\left[\mathrm{N}(\mathrm{CN})_{2}\right]$, and $\left[\mathrm{C}_{\mathrm{n}} \mathrm{mpyr}\right] \mathrm{Cl}(\mathrm{n}=1-4)$ for which conductivity data have not been published.

A similar trend observed for melting points is that the dicyanamide ionic liquids form a good correlation between the dispersion component and conductivity with the MAE of $6.6 \mathrm{mS} \mathrm{cm}^{-1}$ and the maximum error of $14 \mathrm{mS} \mathrm{cm}^{-1}$. Conductivities have been predicted using molecular dynamics with a mean absolute error of $23 \% .^{22,113}$ This represents an excellent result, considering that the ionic liquid conductivity data span a range of $57.7 \mathrm{mS} \mathrm{cm}^{-1}$. The imidazolium-based ionic liquids coupled with tetrafluoroborates and chloride anions produce excellent correlations with the MAE as low as $2.2 \mathrm{mS} \mathrm{cm}-1$ and the maximum error of $4.6 \mathrm{mS} \mathrm{cm}^{-1}$, with both tetrafluoroborate and chloride systems performing equally well and producing MAE \pm SD of $2.4 \pm 2.9$ and $1.9 \pm 2.9$, respectively. It has to be noticed that the series of the $\left[\mathrm{C}_{n} \mathrm{mpyr}\right]\left[\mathrm{BF}_{4}\right]$ ionic liquids $(n=1-4)$ do not seem to correlate with the dispersion component due to very low values of conductivity ranging from $4.2 \times 10^{-11}$ to $8.8 \times 10^{-7} \mathrm{mS} \mathrm{cm} \mathrm{cm}^{-1}$. To this end, it appears that good correlations between conductivity and the dispersion component can already be achieved for 2 ion-paired models.

\section{CONCLUSIONS}

In this work, two ion-paired clusters of $\left[\mathrm{C}_{\mathrm{n}} \mathrm{mim}\right] \mathrm{X}$ and $\left[\mathrm{C}_{\mathrm{n}} \mathrm{mpyr}\right] \mathrm{X}(\mathrm{n}=1-4)$, where $\mathrm{X}=\mathrm{BF}_{4}{ }^{-}, \mathrm{Cl}^{-}$, and $\mathrm{N}(\mathrm{CN})_{2}{ }^{-}$, have been studied with the newly developed SRS-MP2 method with the view of predicting their thermodynamic (such as melting point) and transport (such as conductivity) properties. Each cation-anion combination was thoroughly screened to locate all possible minima and hence global minima on the potential energy surfaces, with 192 unique structures being identified. Increasing alkyl chain on the cation leads to an increased number of lower energy configurations as do anions with multiple interaction sites. Based on the analysis of the lowest energy configurations, it can be concluded that both cation and anion play a role in governing the most stable structure, opposed to the general belief that the anion was the main driving force. The preference for the $\pi^{+}-\pi^{+}$stacking interaction was only observed for imidazolium-based ionic liquids when coupled with the chloride anion, whereas both tetrafluoroborate and dicyanamide preferred alternating charge arrangement. In the case of pyrrolidinium-based ionic liquids, the position of the alkyl groups appeared to be dictated by the anion. In the case of anions with multiple interaction sites such as tetrafluoroborate 
and dicyanamide, longer alkyl chains preferred to align with each other in order to further increase the cluster stability.

Out of the two criteria, interaction energy and total electronic energy, the latter was found to be less biased due to the inclusion of deformation energy of constituting ions. Although interaction energy is often used to identify the stability of intermolecular complexes in the field of theoretical chemistry, the deformation energy was found to be far from negligible in two ion-paired ionic liquid clusters, reaching up to $27 \mathrm{~kJ} \mathrm{~mol}^{-1}$ for imidazolium ionic liquids. This study clearly highlights the importance of using total electronic energy to determining the most stable structures from quantum chemical calculations.

The dispersion component of interaction energy was found to increase up to three-fold going from 1 to 2 ionpaired systems. The relative contribution of dispersion fell between $12.0 \%$ and $16.2 \%$ for $\mathrm{BF}_{4}{ }^{-}$- and $\mathrm{Cl}^{-}$-based ionic liquids, whereas dicyanamide salts exhibited the highest dispersion component reaching $22 \%$. The most striking difference to the single ion pair model results lies in the fact that no appreciable differences in the relative dispersion component were found between imidazolium and pyrrolidinium ionic liquids when coupled with the same anion.

The previously suggested correlation between the ratio of interaction energy to its dispersion component and experimentally measured melting points was tested for 2 ion paired systems. Contrary to the single ion pair model, the ionic liquids studied now formed a good correlation with the MAE of $54 \mathrm{~K}$ which is comparable to the accuracy of current $\mathrm{MD}$ simulations. The $\left[\mathrm{C}_{\mathrm{n}} \mathrm{mim}\right]\left[\mathrm{BF}_{4}\right]$ ionic liquids that appeared to produce their own correlation with the largest deviations were observed for $\left[\mathrm{C}_{\mathrm{n}} \mathrm{mpyr}\right]\left[\mathrm{BF}_{4}\right]$ and $\left[\mathrm{C}_{\mathrm{n}} \mathrm{mim}\right] \mathrm{Cl}$. The former belongs to the class of plastic crystals that undergo solid-solid transitions that result in higher melting points. The entropic effects appear to play a particularly important role for these ionic liquids, thus highlighting the limitation of our approach. Dicyanamide-based ionic liquids generated the best correlation, with the MAE as low as $21 \mathrm{~K}$. Two distinct trends were observed for the prediction of conductivity. One includes $\left[\mathrm{C}_{\mathrm{n}} \mathrm{mim}\right]\left[\mathrm{BF}_{4}\right]$ and $\left[\mathrm{C}_{\mathrm{n}} \mathrm{mim}\right] \mathrm{Cl}$ ionic liquids, whose conductivity can be predicted with the MAE of $2.2 \mathrm{mS} \mathrm{cm}^{-1}$. The second trend was formed by the $\mathrm{N}(\mathrm{CN})_{2}{ }^{-}$ionic liquids with the MAE of $6.6 \mathrm{mS} \mathrm{cm}^{-1}$. Good correlations for both melting point and conductivity represent a significant improvement over the single ion pair model, thus highlighting the importance of many-body effects in ionic liquids induced by interionic interactions of the same charge. It is also suggested that such good correlations could only be achieved due to the use of the recently developed SRS-MP2 method that shows high accuracy $\left(2 \mathrm{~kJ} \mathrm{~mol}^{-1}\right.$ on average) for the prediction of dispersion forces in large-scale clusters of ionic liquids. In addition, a reliable scaled HF method was proposed to predict interaction energies of large-scale clusters of ionic liquids with a relatively small basis set and without the need to account for counterpoise correction.

In summary, the proposed approach of correlating the interaction energy and its dispersion component with thermodynamic and transport properties has been successful when applied to two ion-paired systems, especially when applied to dicyanamide-based ionic liquids. Further improvement is expected for spherical anions such as tetrafluoroborates and chloride when larger-scale clusters are considered. Currently a study is underway to identify whether the inclusion of 4 ion pairs in the cluster would further result in the improvement of the established correlations.

\section{SUPPLEMENTARY MATERIAL}

See supplementary material for the literature melting points, conductivity, and interaction energies for the correlations of ionic liquids.

\section{ACKNOWLEDGMENTS}

The authors acknowledge generous support from the Australian Research Council through a Discovery Project Grant and a Future Fellowship for E.I.I. Z.L.S. is grateful to the Department of Education and Training for an Australian Postgraduate Award.

${ }^{1}$ S. J. Andersen, J. K. E. T. Berton, P. Naert, S. Gildemyn, K. Rabaey, and C. V. Stevens, ChemSusChem 9, 2059-2063 (2016).

${ }^{2}$ S. Bhattacharyya, A. Filippov, and F. Shah, Phys. Chem. Chem. Phys. 18, 28617-28625 (2016).

${ }^{3}$ N. Daud, E. Bakis, J. P. Hallett, C. C. Weber, and T. Welton, Chem. Commun. 53, 11154-11156 (2017).

${ }^{4}$ G. F. Gregorio, C. C. Weber, J. Gräsvik, T. Welton, A. Brandt, and J. P. Hallett, Green Chem. 18, 5456-5465 (2016).

${ }^{5}$ J. P. Hallett and T. Welton, Chem. Rev. 111, 3508-3576 (2011).

${ }^{6}$ A. Izgorodin, E. Izgorodina, and D. R. MacFarlane, Energy Environ. Sci. 5, 9496-9501 (2012).

${ }^{7}$ S. Kwon, J. Choi, S. Cho, H. Lee, W. Oh, and S.-J. Choi, J. Radioanal. Nucl. Chem. 311, 1605-1611 (2016).

${ }^{8}$ J. V. Langham, R. A. O'Brien, J. H. Davis, and K. N. West, J. Phys. Chem. B 120, 10524-10530 (2016).

${ }^{9}$ T. Lee, S. Oh, T. R. Gohndrone, O. Morales-Collazo, S. Seo, J. F. Brennecke, and W. F. Schneider, J. Phys. Chem. B 120, 1509-1517 (2016).

${ }^{10} \mathrm{~S}$. Menne, T. Vogl, and A. Balducci, Chem. Commun. 51, 3656-3659 (2015).

${ }^{11}$ A. Rout, K. A. Venkatesan, T. G. Srinivasan, and V. P. R. Rao, Solvent Extr. Ion Exch. 29, 602-618 (2011).

${ }^{12}$ B. Kirchner, O. Hollóczki, J. N. Canongia Lopes, and A. A. H. Pádua, Wiley Interdiscip. Rev.: Comput. Mol. Sci. 5, 202-214 (2014).

${ }^{13}$ E. I. Izgorodina, Z. L. Seeger, D. L. A. Scarborough, and S. Y. S. Tan, Chem. Rev. 117, 6696-6754 (2017).

${ }^{14}$ K. Shimizu, A. Pensado, P. Malfreyt, A. A. H. Pádua, and J. N. Lopes, Faraday Discuss. 154, 155-169 (2011).

${ }^{15}$ S. Lectez, J. Roques, M. Salanne, and E. Simoni, J. Chem. Phys. 137, 154705 (2012).

${ }^{16}$ F. Dommert, J. Schmidt, B. Qiao, Y. Zhao, C. Krekeler, L. Site, R. Berger, and C. Holm, J. Chem. Phys. 129, 224501 (2008).

${ }^{17}$ W. Jiang, D. J. Hardy, J. C. Phillips, A. D. MacKerell, K. Schulten, and B. Roux, J. Phys. Chem. Lett. 2, 87-92 (2011).

${ }^{18}$ C. Merlet, M. Salanne, B. Rotenberg, and P. A. Madden, J. Phys. Chem. C 115, 16613-16618 (2011).

${ }^{19}$ T. Mev́ndez-Morales, J. Carrete, O. Cabeza, L. J. Gallego, and L. M. Varela, J. Phys. Chem. B 115, 6995-7008 (2011).

${ }^{20}$ A. Kandratsenka, J. Schroeder, D. Schwarzer, and V. S. Vikhrenko, J. Chem. Phys. 130, 174507 (2009).

${ }^{21}$ A. C. F. Mendonça, A. A. H. Pádua, and P. Malfreyt, J. Chem. Theory Comput. 9, 1600-1610 (2013).

${ }^{22}$ O. Borodin, J. Phys. Chem. B 113, 11463-11478 (2009).

${ }^{23}$ J. C. Wu, J.-P. Piquemal, R. Chaudret, P. Reinhardt, and P. Ren, J. Chem. Theory Comput. 6, 2059-2070 (2010).

${ }^{24}$ K. Shimizu and J. N. Lopes, J. Mol. Liq. 210, 257-263 (2015).

${ }^{25}$ F. Lipparini, L. Lagardère, B. Stamm, E. Cancès, M. Schnieders, P. Ren, Y. Maday, and J.-P. Piquemal, J. Chem. Theory Comput. 10, 1638-1651 (2014). 
${ }^{26}$ A. Dequidt, J. Devémy, and A. A. H. Pádua, J. Chem. Inf. Model. 56, 260-268 (2016)

${ }^{27}$ J.-M. Andanson, E. Bordes, J. Devémy, F. Leroux, A. A. H. Pádua, and M. F. Gomes, Green Chem. 16, 2528-2538 (2014).

${ }^{28}$ E. I. Izgorodina, D. Golze, R. Maganti, and V. Armel, Phys. Chem. Chem. Phys. 16, 7209-7221 (2013); E. I. Izgorodina et al., ibid. 16, 7129 (2014).

${ }^{29}$ E. I. Izgorodina, and U. L. Bernard, J. Phys. Chem. A 113, 7064-7072 (2009).

${ }^{30}$ S. Tan, S. Barrera Acevedo, and E. I. Izgorodina, J. Chem. Phys. 146, 064108 (2017).

${ }^{31}$ N. V. Plechkova and K. R. Seddon, Chem. Soc. Rev. 37, 123-150 (2008).

${ }^{32}$ C. M. Gordon, J. D. Holbrey, A. R. Kennedy, and K. R. Seddon, J. Mater. Chem. 8, 2627-2636 (1998).

${ }^{33}$ J. D. Holbrey and S. Seddon, J. Chem. Soc., Dalton Trans. 2133-2140 (1999).

${ }^{34}$ R. N. D. Das and K. Roy, Mol. Diversity 17, 151-196 (2013).

${ }^{35}$ D. C. Weis and D. R. MacFarlane, Aust. J. Chem. 65, 1478-1486 (2012).

${ }^{36}$ J. O. Valderrama, Ind. Eng. Chem. Res. 53, 1004-1014 (2014).

${ }^{37}$ H. D. B. Jenkins, D. Tudela, and L. Glasser, Inorg. Chem. 41, 2364-2367 (2002).

${ }^{38}$ H. D. B. Jenkins, H. K. Roobottom, J. Passmore, and L. Glasser, Inorg. Chem. 38, 3609-3620 (1999).

${ }^{39}$ A. Klamt, Wiley Interdiscip. Rev.: Comput. Mol. Sci. 1, 699-709 (2011).

${ }^{40}$ A. Klamt, F. Eckert, and W. Arlt, Annu. Rev. Chem. Biomol. Eng. 1, 101$122(2010)$.

${ }^{41}$ K. E. Gutowski, J. D. Holbrey, R. D. Rogers, and D. D. Dixon, J. Phys. Chem. B 109, 23196-23208 (2005).

${ }^{42}$ U. Preiss, S. Bulut, and I. Krossing, J. Phys. Chem. B 114, 11133-11140 (2010).

${ }^{43}$ P. Eiden, S. Bulut, T. Köchner, C. Friedrich, T. Schubert, and I. Krossing, J. Phys. Chem. B 115, 300-309 (2010).

${ }^{44}$ K. Dong, L. Zhao, Q. Wang, Y. Song, and S. Zhang, Phys. Chem. Chem. Phys. 15, 6034-6040 (2013).

${ }^{45}$ C. Spickermann, S. C. Lehmann, and B. Kirchner, J. Chem. Phys. 128, 244506 (2008).

${ }^{46}$ R. Ludwig, Phys. Chem. Chem. Phys. 10, 4333-4339 (2008).

${ }^{47}$ V. N. Emel'yanenko, G. Boeck, S. P. Verevkin, and R. Ludwig, Chem. - Eur. J. 20, 11640-11645 (2014).

${ }^{48}$ K. Fumino, T. Peppel, M. Geppert-Rybczynska, D. H. Zaitsau, J. K. Lehmann, S. P. Verevkin, M. Köckerling, and R. Ludwig, Phys. Chem. Chem. Phys. 13, 14064-14075 (2011).

${ }^{49}$ T. Peppel, C. Roth, K. Fumino, P. Paschek, M. Kockerling, and R. Ludwig, Angew. Chem., Int. Ed. 50, 6661-6665 (2011).

${ }^{50}$ F. Weinhold, J. Chem. Phys. 109, 367-372 (1998).

${ }^{51}$ F. Weinhold, J. Chem. Phys. 109, 373-384 (1998).

${ }^{52}$ R. Ludwig, F. Weinhold, and T. C. Farrar, J. Chem. Phys. 102, 5118-5125 (1995).

${ }^{53}$ R. Ludwig, ChemPhysChem 6, 1376-1380 (2005).

${ }^{54}$ R. Ludwig, F. Weinhold, and T. C. Farrar, Ber. Bunsenges. Phys. Chem. 102, 205-212 (1998).

${ }^{55}$ R. Ludwig and F. Weinhold, J. Chem. Phys. 110, 508-515 (1999).

${ }^{56}$ R. Ludwig, F. Weinhold, and T. C. Farrar, Mol. Phys. 97, 479-486 (1999).

${ }^{57}$ R. Ludwig, F. Weinhold, and T. C. Farrar, Mol. Phys. 97, 465-477 (1999).

${ }^{58}$ R. Ludwig, ChemPhysChem 6, 1369-1375 (2005).

${ }^{59}$ R. Ludwig, F. Weinhold, and T. C. Farrar, J. Chem. Phys. 107, 499-507 (1997).

${ }^{60}$ B. Kirchner, J. Chem. Phys. 123, 204116 (2005)

${ }^{61}$ J. Friedrich, E. Perlt, M. Roatsch, C. Spickermann, and B. Kirchner, J. Chem. Theory Comput. 7, 843-851 (2011).

${ }^{62}$ C. Spickermann, E. Perlt, M. von Domaros, M. Roatsch, J. Friedrich, and B. Kirchner, J. Chem. Theory Comput. 7, 868-887 (2011).

${ }^{63}$ K. Fumino, A. Wulf, and R. Ludwig, Phys. Chem. Chem. Phys. 11, 87908794 (2009)

${ }^{64}$ K. Fumino, A. Wulf, and R. Ludwig, Angew. Chem., Int. Ed. 48, 3184-3186 (2009).

${ }^{65}$ K. Fumino, A. Wulf, and R. Ludwig, Angew. Chem., Int. Ed. 47, 3830-3834 (2008).

${ }^{66}$ A. Wulf, K. Fumino, R. Ludwig, and P. F. Taday, ChemPhysChem 11, 349-353 (2010)

${ }^{67}$ K. Fumino, V. Fossog, P. Stange, K. Wittler, W. Polet, R. Hempelmann, and R. Ludwig, ChemPhysChem 15, 2604-2609 (2014).

${ }^{68}$ E. A. Turner, C. C. Pye, and R. D. Singer, J. Phys. Chem. A 107, 2277-2288 (2003).
${ }^{69}$ S. Zahn, G. Bruns, J. Thar, and B. Kirchner, Phys. Chem. Chem. Phys. 10, 6921-6924 (2008).

${ }^{70}$ E. I. Izgorodina, J. Rigby, and D. R. MacFarlane, Chem. Commun. 48, 1493-1495 (2011).

${ }^{71}$ P. Halet, Z. L. Seeger, S. Barrera Acevedo, and E. I. Izgorodina, J. Phys. Chem. B 121, 577-588 (2017).

${ }^{72}$ K. Muller-Dethlefs and P. Hobza, Chem. Rev. 100, 143-168 (2000).

${ }^{73}$ J. Rezac and P. Hobza, Chem. Rev. 116, 5038-5071 (2016).

${ }^{74}$ J. Rigby and E. I. Izgorodina, Phys. Chem. Chem. Phys. 15, 1632-1646 (2012).

${ }^{75}$ O. Hollóczki, F. Malberg, T. Welton, and B. Kirchner, Phys. Chem. Chem. Phys. 16, 16880-16890 (2014).

${ }^{76}$ P. A. Hunt, J. Phys. Chem. B 111, 4844-4853 (2007).

${ }^{77}$ P. A. Hunt, I. R. Gould, and B. Kirchner, Aust. J. Chem. 60, 9-14 (2007).

${ }^{78}$ D. G. Fedorov and K. Kitaura, Chem. Phys. Lett. 389, 129-134 (2004).

${ }^{79}$ D. G. Fedorov, R. M. Olson, and K. Kitaura, J. Comput. Chem. 25, 872-880 (2004).

${ }^{80}$ J. Rigby, S. Barrera Acevedo, and E. I. Izgorodina, J. Chem. Theory Comput. 11, 3610-3616 (2015).

${ }^{81}$ M. W. Schmidt, K. K. Baldridge, J. A. Boatz, S. T. Elbert, M. S. Gordon, J. H. Jensen, S. Koseki, N. Matsunaga, K. A. Nguyen, and S. Su, J. Comput Chem. 14, 1347-1363 (1993).

${ }^{82}$ R. M. Parrish, L. A. Burns, and D. G. A. Smith, A. C. Simmonett, A. DePrince, E. G. Hohenstein, U. Bozkaya, A. Y. Sokolov, R. D. Remigio, R. M. Richard, J. F. Gonthier, A. M. James, H. R. McAlexander, A. Kumar, M. Saitow, X. Wang, B. P. Pritchard, P. Verma, H. F. Schaefer, K. Patkowski, R. A. King, E. F. Valeev, F. A. Evangelista, J. M. Turney, T. D. Crawford, and C. D. Sherrill, J. Chem. Theory Comput. 13, 3185-3197 (2017).

${ }^{83}$ M. J. Frisch, G. W. Trucks, H. B. Schlegel, G. E. Scuseria, M. A. Robb, J. R. Cheeseman, G. Scalmani, V. Barone, B. Mennucci, G. A. Petersson, H. Nakatsuji, M. Caricato, X. Li, H. P. Hratchian, A. F. Izmaylov, J. Bloino, G. Zheng, J. L. Sonnenberg, M. Hada, M. Ehara, K. Toyota, R. Fukuda, J. Hasegawa, M. Ishida, T. Nakajima, Y. Honda, O. Kitao, H. Nakai, T. Vreven, J. A. Montgomery, J. E. Peralta, F. Ogliaro, M. Bearpark, J. J. Heyd, E. Brothers, K. N. Kudin, V. N. Staroverov, R. Kobayashi, J. Normand, K. Raghavachari, A. Rendell, J. C. Burant, S. S. Iyengar, J. Tomasi, M. Cossi, N. Rega, J. M. Millam, M. Klene, J. E. Knox, J. B. Cross, V. Bakken, C. Adamo, J. Jaramillo, R. Gomperts, R. E. Stratmann, O. Yazyev, A. J. Austin, R. Cammi, C. Pomelli, J. W. Ochterski, R. L. Martin, K. Morokuma, V. G. Zakrzewski, G. A. Voth, P. Salvador, J. J. Dannenberg, S. Dapprich, A. D. Daniels, Farkas, J. B. Foresman, J. V. Ortiz, J. Cioslowski, and D. J. Fox, Gaussian 09, Revision E.01, Gaussian, Inc., Wallingford, CT, 2016.

${ }^{84}$ R. P. Matthews, T. Welton, and P. A. Hunt, Phys. Chem. Chem. Phys. 16, 3238-3253 (2014).

${ }^{85}$ R. P. Matthews, T. Welton, and P. A. Hunt, Phys. Chem. Chem. Phys. 17, 14437-14453 (2015).

${ }^{86}$ R. P. Matthews, C. Ashworth, T. Welton, and P. A. Hunt, J. Phys.: Condens. Matter 26, 284112 (2014).

${ }^{87}$ S. Grimme, J. Antony, S. Ehrlich, and H. Krieg, J. Chem. Phys. 132, 154104 (2010).

${ }^{88}$ S. Grimme, Wiley Interdiscip. Rev.: Comput. Mol. Sci. 1, 211-228 (2011).

${ }^{89}$ S. Grimme, A. Hansen, J. Brandenburg, and C. Bannwarth, Chem. Rev. 116, 5105-5154 (2016)

${ }^{90}$ S. Zahn, D. R. MacFarlane, and E. I. Izgorodina, Phys. Chem. Chem. Phys 15, 13664-13675 (2013).

${ }^{91}$ E. I. Izgorodina, D. Golze, R. Maganti, and V. Armel, Phys. Chem. Chem. Phys. 16, 7209-7221 (2013).

${ }^{92}$ J. Rigby and E. I. Izgorodina, J. Chem. Theory Comput. 10, 3111-3122 (2014).

${ }^{93}$ S. F. Boys and F. Bernardi, Mol. Phys. 19, 553-566 (2006).

${ }^{94}$ F. Jensen, J. Chem. Phys. 110, 6601-6605 (1999).

${ }^{95}$ A. Halkier, T. Helgaker, P. Jorgensen, W. Klopper, and J. Olsen, Chem. Phys. Lett. 302, 437-446 (1999).

${ }^{96}$ A. Karton and J. M. L. Martin, Theor. Chem. Acc. 115, 330-333 (2006).

${ }^{97}$ M. Newville, T. Stensitzki, D. B. Allen, and A. Ingargiola, LMFIT: NonLinear Least-Square Minimization and Curve-Fitting for Python (2014).

${ }^{98}$ K. Fumino, V. Fossog, P. Stange, D. Paschek, R. Hempelmann, and R. Ludwig, Angew. Chem., Int. Ed. 54, 2792-2795 (2015).

${ }^{99}$ L. Scarbath-Evers, P. A. Hunt, B. Kirchner, D. R. MacFarlane, and S. Zahn, Phys. Chem. Chem. Phys. 17, 20205-20216 (2015).

${ }^{100}$ M. Levitt, J. Mol. Biol. 170, 723-764 (1983).

${ }^{101}$ S. Erkoc and E. Guneyler, Phys. E 8, 40-49 (2000).

102 A. Ince and S. Erkoc, Comput. Mater. Sci. 50, 865-870 (2011). 
${ }^{103}$ B. Leimkuhler, C. Matthews, B. Leimkuhler, and C. Matthews, Molecular Dynamics With Deterministic and Stochastic Numerical Methods (Springer, 2015), Vol. 39, pp. 211-260.

${ }^{104}$ E. J. Maginn, Acc. Chem. Res. 40, 1200-1207 (2007).

${ }^{105}$ D. M. Eike, J. F. Brennecke, and E. J. Maginn, Green Chem. 5, 323-328 (2003).

${ }^{106}$ S. Jayaraman and E. J. Maginn, J. Chem. Phys. 127, 214504 (2007).

${ }^{107}$ L. Glasser, Thermochim. Acta 421, 87-93 (2004).

${ }^{108}$ S. Forsyth, J. Golding, D. R. MacFarlane, and M. Forsyth, Electrochim. Acta 46, 1753-1757 (2001).
${ }^{109}$ J. Golding, N. Hamid, D. R. MacFarlane, M. Forsyth, C. Forsyth, C. Collins, and J. Huang, Chem. Mater. 13, 558-564 (2001).

${ }^{110}$ W. A. Henderson, V. G. Young, S. Passerini, P. C. Trulove, and H. C. DeLong, Chem. Mater. 18, 934-938 (2006).

${ }^{111}$ D. R. MacFarlane, P. Meakin, J. Sun, N. Amini, and M. Forsyth, J. Phys. Chem. B 103, 4164-4170 (1999).

${ }^{112}$ T. Kanatani, R. Ueno, K. Matsumoto, T. Nohira, and R. Hagiwara, J. Fluorine Chem. 130, 979-984 (2009).

${ }^{113}$ B. L. Bhargava and S. Balasubramanian, J. Chem. Phys. 123, 144505 (2005). 